\title{
A Method for Extrapolation of Atmospheric Soundings
}

\author{
by James Cogan and Brian Reen
}

ARL-TR-6930

May 2014

Approved for public release; distribution unlimited. 


\section{NOTICES}

\section{Disclaimers}

The findings in this report are not to be construed as an official Department of the Army position unless so designated by other authorized documents.

Citation of manufacturer's or trade names does not constitute an official endorsement or approval of the use thereof.

Destroy this report when it is no longer needed. Do not return it to the originator. 


\title{
Army Research Laboratory
}

Adelphi, MD 20783-1197

ARL-TR-6930

May 2014

\section{A Method for Extrapolation of Atmospheric Soundings}

\author{
James Cogan and Brian Reen \\ Computational and Information Sciences Directorate, ARL
}




\section{REPORT DOCUMENTATION PAGE}

Public reporting burden for this collection of information is estimated to average 1 hour per response, including the time for reviewing instructions, searching existing data sources, gathering and maintaining the data needed, and completing and reviewing the collection information. Send comments regarding this burden estimate or any other aspect of this collection of information, including suggestions for reducing the burden, to Department of Defense, Washington Headquarters Services, Directorate for Information Operations and Reports (0704-0188), 1215 Jefferson Davis Highway, Suite 1204, Arlington, VA 22202-4302. Respondents should be aware that notwithstanding any other provision of law, no person shall be subject to any penalty for failing to comply with a collection of information if it does not display a currently valid OMB control number.

PLEASE DO NOT RETURN YOUR FORM TO THE ABOVE ADDRESS.

\begin{tabular}{|c|c|c|}
\hline $\begin{array}{l}\text { 1. REPORT DATE (DD-MM-YYYY) } \\
\text { May } 2014\end{array}$ & $\begin{array}{l}\text { 2. REPORT TYPE } \\
\text { Final }\end{array}$ & $\begin{array}{l}\text { 3. DATES COVERED (From - To) } \\
10 / 2013 \text { to } 3 / 2014\end{array}$ \\
\hline \multirow{4}{*}{\multicolumn{2}{|c|}{$\begin{array}{l}\text { 4. TITLE AND SUBTITLE } \\
\text { A Method for Extrapolation of Atmospheric Soundings }\end{array}$}} & 5a. CONTRACT NUMBER \\
\hline & & \\
\hline & & 5b. GRANT NUMBER \\
\hline & & 5c. PROGRAM ELEMENT NUMBER \\
\hline \multirow{4}{*}{\multicolumn{2}{|c|}{$\begin{array}{l}\text { 6. AUTHOR(S) } \\
\text { James Cogan and Brian Reen }\end{array}$}} & 5d. PROJECT NUMBER \\
\hline & & \\
\hline & & 5e. TASK NUMBER \\
\hline & & 5f. WORK UNIT NUMBER \\
\hline $\begin{array}{l}\text { 7. PERFORMING ORGANIZATION } \\
\text { U.S. Army Research Labora } \\
\text { ATTN: RDRL CIE } \\
\text { 2800 Powder Mill Road } \\
\text { Adelphi MD 20783-1197 }\end{array}$ & S) AND ADDRESS(ES) & $\begin{array}{l}\text { 8. PERFORMING ORGANIZATION } \\
\text { REPORT NUMBER } \\
\text { ARL-TR-6930 }\end{array}$ \\
\hline \multirow{2}{*}{\multicolumn{2}{|c|}{ 9. SPONSORING/MONITORING AGENCY NAME(S) AND ADDRESS(ES) }} & 10. SPONSOR/MONITOR'S ACRONYM(S) \\
\hline & & $\begin{array}{l}\text { 11. SPONSOR/MONITOR'S REPORT } \\
\text { NUMBER(S) }\end{array}$ \\
\hline
\end{tabular}

\section{DISTRIBUTION/AVAILABILITY STATEMENT}

Approved for public release; distribution unlimited.

13. SUPPLEMENTARY NOTES

\section{ABSTRACT}

Meteorological models use terrain databases with resolutions on the order of model grid intervals (e.g., a terrain grid spacing of $4 \mathrm{~km}$ for a model with 4-km spacing). Generally, model software smoothes the terrain to a coarser resolution for computational stability (e.g., a 4-km grid model may have terrain smoothed to about $10 \mathrm{~km}$ ). In more complex terrain, the difference between the smoothed terrain and actual elevation could reach hundreds of meters, perhaps $>1000 \mathrm{~m}$ for mountainous regions. To obtain meteorological information between the actual height and the model height or a nearby rawinsonde, current methods often use the temperature at the lowest level (nominal surface) and assume a standard lapse rate down to the level of interest, which is normally the elevation of the actual surface or of a finer terrain database. Pressure is computed from temperature and height. Many methods keep the surface wind speed and direction constant throughout the extrapolated section of the profile. These methods are often used to extrapolate an observed sounding (e.g., radiosonde) to a nearby lower elevation. Our method extracts information from the model-generated atmospheric profile or measured sounding to help generate the extrapolated profile. It takes into account surface-based inversions, although, at present, does not explicitly account for elevated inversions.

\section{SUBJECT TERMS}

extrapolation, atmospheric sounding

\begin{tabular}{|l|l|l|l|l|l|}
\hline \multicolumn{2}{|l|}{ 16. SECURITY CLASSIFICATION OF: } & $\begin{array}{l}\text { 17. LIMITATION } \\
\text { OF } \\
\text { ABSTRACT }\end{array}$ & $\begin{array}{l}\text { 18. NUMBER } \\
\text { OF } \\
\text { PAGES }\end{array}$ & $\begin{array}{l}\text { 19a. NAME OF RESPONSIBLE PERSON } \\
\text { James Cogan }\end{array}$ \\
\cline { 1 - 2 } $\begin{array}{l}\text { A. Report } \\
\text { Unclassified }\end{array}$ & b. ABSTRACT & c. THIS PAGE & UU & 46 & $\begin{array}{l}\text { 19b. TELEPHONE NUMBER (Include area code) } \\
(301) 394-2304\end{array}$ \\
\hline
\end{tabular}




\section{Contents}

List of Figures $\quad$ iv

$\begin{array}{lc}\text { List of Tables } & \mathbf{v}\end{array}$

$\begin{array}{ll}\text { 1. Introduction } & 1\end{array}$

2. Method 2

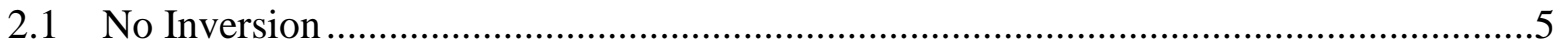

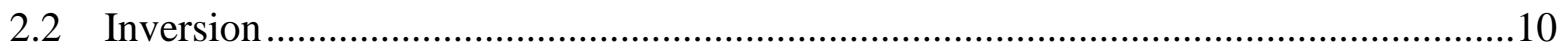

2.2.1 Extrapolation Depth Greater Than Inversion Depth ....................................10

2.2.2 Extrapolation Depth Less Than or Equal to Inversion Depth ........................11

3. Sample Output 12

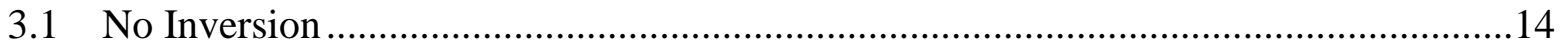

3.1.1 Comparison with Radiosonde ...............................................................14

3.1.2 WRF Inter-Comparisons .................................................................... 18

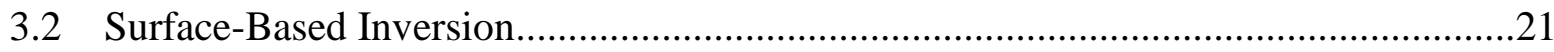

3.2.1 Extrapolation Depth Greater Than Inversion Depth ...................................21

3.2.2 Extrapolation Depth Less Than Inversion Depth ........................................27

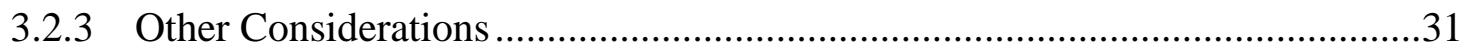

4. Summary and Conclusion $\quad 32$

$\begin{array}{ll}\text { 5. } & \text { References } \\ \end{array}$

$\begin{array}{ll}\text { List of Symbols, Abbreviations, and Acronyms } & 34\end{array}$

$\begin{array}{ll}\text { List of Variables } & 35\end{array}$

$\begin{array}{ll}\text { Distribution List } & 37\end{array}$ 


\section{List of Figures}

Figure 1. Schematic of some of the levels involved in the extrapolation where the extrapolation depth is $h_{\text {ext }}$. The input data's surface is the old surface $\left(\mathrm{z}_{\text {oldsfc }}\right)$ and the algorithm extrapolates through the extrapolation layer down to the new surface $\left(\mathrm{Z}_{\text {newsfc }}\right)$. Shown are an example input profile extending upward from the old surface and an example output profile after being extrapolated downward to the new surface.

Figure 2. Three types of atmospheric temperature profiles accounted for by the extrapolation algorithm. From left to right: no inversion, top of inversion $\left(h_{i n v}\right)$ below the extrapolation depth $\left(h_{\text {ext }}\right)$, and $h_{\text {inv }}$ above $h_{\text {ext }}$. Not shown are the cases of an elevated inversion or where $h_{\text {inv }}=h_{\text {ext }}$. If $h_{\text {inv }}=h_{\text {ext }}$, then the algorithm uses the same procedure as with $h_{\text {inv }}>h_{\text {ext }} \ldots \ldots \ldots . .3$

Figure 3. Schematic demonstrating the procedure used to extrapolate wind. .............................7

Figure 4. Schematic illustrating the computation of layer values for each height and the total mean value.

Figure 5. Profiles comparing the 00 UTC 14 January 2013 GJT radiosonde to 1-km WRF data from 23 UTC extended from the "old surface" to the radiosonde surface using the standard extrapolation and the extrapolation method proposed here for (a) temperature and (b) wind speed.

Figure 6. Profiles comparing 1-km WRF data and 3-km WRF data extended from the "old surface" to the radiosonde surface using the standard extrapolation and extended using the extrapolation method proposed here at a site in an area centered on southern California, latitude $33.264 \mathrm{~N}$ and $116.826 \mathrm{~W}$, at $22 \mathrm{UTC}$ on 09 February 2013 for (a) temperature and (b) wind speed.

Figure 7. Profiles comparing the 12 UTC 14 January 2013 GJT radiosonde to 9-km WRF data extended from the "old surface" to the radiosonde surface using the standard extrapolation and the extrapolation method proposed here for (a) temperature and (b) wind speed.

Figure 8. Profiles comparing the 12 UTC 14 January 2013 GJT radiosonde to 3-km WRF data extended from the "old surface" to the radiosonde surface using the standard extrapolation and the extrapolation method proposed here for (a) temperature and (b) wind speed.

Figure 9. Profiles comparing the 12 UTC 12 January 2013 ZXS radiosonde to 9-km WRF data extended from the "old surface" to the radiosonde surface using the standard extrapolation and the extrapolation method proposed here for (a) temperature and (b) wind speed. 


\section{List of Tables}

Table 1. Radiosonde sounding for GJT on 14 January 2013 or the 00 UTC sounding. The latitude and longitude are $39.11 \mathrm{~N}$ and $108.53 \mathrm{~W}$, respectively, with an elevation of $1475 \mathrm{~m}$, showing data levels from the surface through $750 \mathrm{hPa}$.

Table 2. Profiles generated from WRF output for a location near GJT at latitude $39.17 \mathrm{~N}$ and 108.49 W at 23 UTC on 13 January 2013. The grid resolution was $1 \mathrm{~km}$ and the elevation from the terrain database to the nearest meter was $1615 \mathrm{~m}$ MSL.

Table 3. Extrapolated profiles generated from 1-km WRF output using our method for the same location and time as table 2. The variables are the same as in table 2, except that HGHT is in AGL and MSL rather than just MSL. The extrapolation depth was $140 \mathrm{~m}$. The levels where the extrapolated profile differs from the original profile in table 2 are highlighted.

Table 4. Profiles generated from WRF output for a site centered on southern California, latitude $33.264 \mathrm{~N}$ and $116.826 \mathrm{~W}$, at 22 UTC on 09 February 2013. The grid resolution was $3 \mathrm{~km}$.

Table 5. Extrapolated profiles generated from the WRF output of table 4. The grid resolution was $3 \mathrm{~km}$. The extrapolation depth was $132 \mathrm{~m}$. Levels with values that differ from table 4 are highlighted.

Table 6. Profiles generated from WRF output for the same location and time as in tables 4 and 5 , but for a grid resolution of $1 \mathrm{~km}$.

Table 7. Radiosonde sounding for GJT on 14 January 2013 at 1200 UTC. The latitude and longitude are $39.11 \mathrm{~N}$ and $108.53 \mathrm{~W}$, respectively, with an elevation of $1475 \mathrm{~m}$. The table shows data levels from the surface through approximately $782 \mathrm{hPa}$.

Table 8. Profiles generated from the WRF 9-km output for the same nominal time as for table 7. The latitude, longitude, and elevation, to the nearest 0.01 degree and meter, respectively, are $39.16 \mathrm{~N}, 108.48 \mathrm{~W}$, and $1634 \mathrm{~m}$.

Table 9. Profiles extrapolated from the WRF 9-km output in table 8. The extrapolation depth was $159 \mathrm{~m}$. The variables and units are the same as in table 8 except height is shown in both AGL and MSL. The levels where the extrapolated profile differs from the original profile in table 8 are highlighted. Note also that the four levels immediately above the surface in table 8 are omitted in the extrapolated profile because they were part of the surface-based inversion that has been moved to the new surface.

Table 10. Profiles generated from the WRF 3-km output for the same nominal time as for table 8. The latitude, longitude, and elevation are $39.16 \mathrm{~N}, 108.48 \mathrm{~W}$, and $1648 \mathrm{~m}$, to the nearest 0.01 degree and meter, respectively. The variables and units are the same as in table 8 . 
Table 11. Profiles extrapolated from the WRF $3-\mathrm{km}$ output in table 10. The extrapolation depth was $173 \mathrm{~m}$. The variables and units are the same as in table 9. The levels where the extrapolated profile differs from the original profile in table 10 are highlighted. Note also that the three levels immediately above the surface in table 10 are omitted in the extrapolated profile because they were part of the surface-based inversion that has been moved to the new surface.

Table 12. Input file from a radiosonde with a surface-based inversion of $337 \mathrm{~m}$ AGL for ZXS. Observations were at 12 UTC on 12 January 2013. Only the lines from the surface through $886 \mathrm{hPa}$ are shown. The variables and units are the same as in table 7.

Table 13. Profiles generated from WRF 9-km output for the same nominal time as for table 12. The latitude, longitude, and elevation, to the nearest 0.01 degree and meter, respectively, are $53.78 \mathrm{~N}, 122.87 \mathrm{~W}$, and $818 \mathrm{~m}$. The variables and units are the same as in table 8 .

Table 14. Extrapolated sounding or profile generated from the sounding of table 13. The extrapolation depth was $217 \mathrm{~m}$ (less than inversion height). The variables and units are the same as in table 8. The levels where the extrapolated profile differs from the original profile in table 13 are highlighted. 


\section{Introduction}

Meteorological models use terrain databases that have resolutions on the order of the model grid intervals. For example, a model with a 4-km grid spacing most likely will have a terrain data set with a resolution (or distance between data points) on the order of $4 \mathrm{~km}$. Furthermore, as a general rule, the model software smoothes the terrain to an even coarser resolution to maintain computational stability. For example, for a 4-km grid model, the smoothed terrain resolution may be closer to something on the order of $10 \mathrm{~km}$. In more complex terrain, the difference between the model (smoothed) terrain elevation and the actual elevation could reach hundreds of meters, perhaps $>1000 \mathrm{~m}$ in extreme cases for mountainous regions.

In order to obtain meteorological information from the actual height of the terrain up to the terrain height of the model or a nearby rawinsonde, current methods often use the temperature at the lowest level (nominal surface) and assume a standard lapse rate down to the level of interest. The level of interest is normally the actual surface elevation or the elevation determined by using a finer terrain database and, in some cases, the finer terrain elevation may be less than that of the coarser terrain.

Pressure normally is computed using the temperature and heights. The relative humidity at the surface may be applied to the entire extrapolated portion of the profile or may be ignored for some applications. In some cases, a method may employ the surface virtual temperature in place of temperature. Many methods also keep the surface wind speed and direction constant throughout the extrapolated profile.

There are variations that compute the percentage of a standard atmosphere temperature for the surface and use that percentage as it relates to standard values to compute the extrapolated temperatures. These types of methods may be used to extrapolate a measured sounding (e.g., radiosonde) to a nearby lower elevation. White (2002) very briefly notes the temperature extrapolation method used at the European Centre for Medium-range Weather Forecasts (ECMWF), which is linear from the lowest model level to the model's terrain surface. The other variables are held constant from the lowest level to "below the surface." Below the surface refers to extrapolation to sea level at standard atmosphere $(1013.25 \mathrm{hPa}[\mathrm{mb}])$ or can refer to another pressure level such as $1000 \mathrm{hPa}$ when the lowest model level is at a lower pressure.

Wang et al. (2013) present more than one option in the Advanced Research Weather Research and Forecasting (ARW) model (Skamarock et al., 2008). The default for temperature uses a standard lapse rate from the lowest level to the surface $(6.5 \mathrm{~K} / \mathrm{km})$. Other options for extrapolating input data onto the ARW vertical grid are to hold temperature or potential temperature constant with height. 
The method described in this report extracts information from a model-generated atmospheric profile or radiosonde sounding to generate the extrapolated profile. It takes into account surfacebased inversions, although, at present, it does not explicitly account for elevated inversions.

\section{Method}

The extrapolation algorithm described herein is intended to be used if the model or measurement site elevation ("old surface," referred to as $\mathrm{z}_{\mathrm{oldsfc}}$ ) is greater than that of the actual or finer-scale terrain elevation ("new surface," referred to as $z_{\text {newsfc }}$ ). The elevation difference between these two surfaces $\left(\mathrm{z}_{\text {oldsfc }}-\mathrm{z}_{\text {newsfc }}\right)$ is referred to as the extrapolation depth $\left(\mathrm{h}_{\mathrm{ext}}\right)$, and the minimum difference where the extrapolation algorithm is used $\left(\mathrm{h}_{\mathrm{extmin}}\right)$ can be any number greater than or equal to zero, but normally would be 0 or only a few meters. For this investigation, $h_{\text {extmin }}$ was set at 0 or $1.0 \mathrm{~m}$. If the elevation difference is less than this value $\left(\mathrm{h}_{\mathrm{ext}}<\mathrm{h}_{\mathrm{extmin}}\right)$, the algorithm simply assigns the old surface values to the new surface for all the variables and does not change values at any other levels. Figure 1 is a schematic of some of the levels involved in the extrapolation.

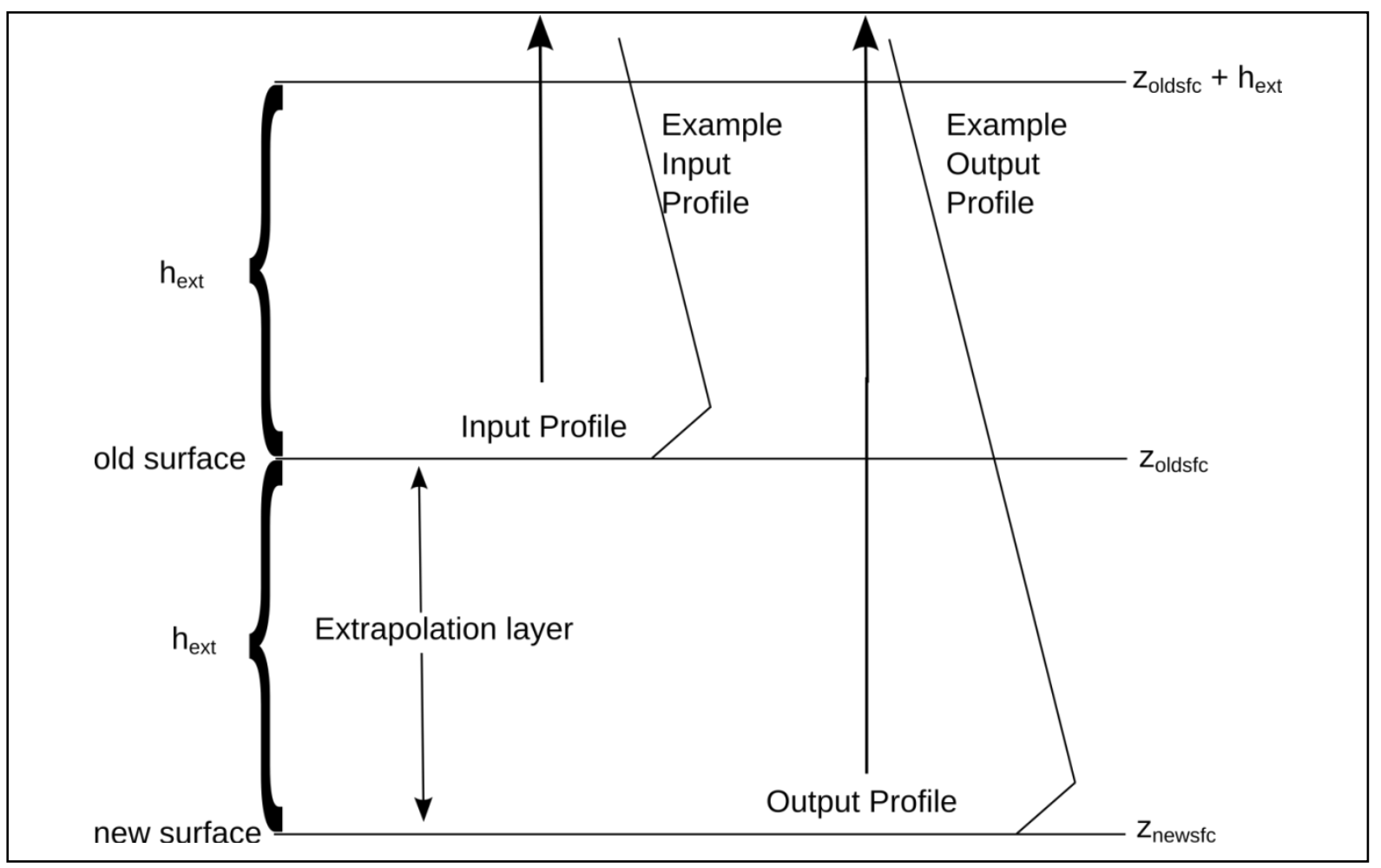

Figure 1. Schematic of some of the levels involved in the extrapolation where the extrapolation depth is $\mathrm{h}_{\mathrm{ext}}$. The input data's surface is the old surface $\left(\mathrm{z}_{\text {oldsfc }}\right)$ and the algorithm extrapolates through the extrapolation layer down to the new surface $\left(\mathrm{z}_{\text {newsfc }}\right)$. Shown are an example input profile extending upward from the old surface and an example output profile after being extrapolated downward to the new surface. 
Figure 2 illustrates the three types of atmospheric profiles treated by the extrapolation method, that is, no inversion, depth of inversion ( $h_{\text {inv }}$ ) less than the extrapolation depth (i.e., $h_{\text {inv }}<h_{\text {ext }}$ ), and depth of inversion greater than the extrapolation depth (i.e., $\mathrm{h}_{\mathrm{inv}}>\mathrm{h}_{\mathrm{ext}}$ ). Not shown are the case of an elevated inversion or the case of the depth of the inversion equal to the extrapolation depth (i.e., $h_{\text {inv }}=h_{\text {ext }}$ ). If they are equal, then the algorithm uses the same procedure as used when the depth of the inversion is greater than the extrapolation depth. Where an elevated inversion occurs, the procedure for no inversion is used, but the method will partly account for that situation since, as is described later, the algorithm will use the average of lapse rates for up to three layers starting at the old surface up to a user-defined maximum inversion depth $\left(\mathrm{h}_{\text {invmax }}\right)$.

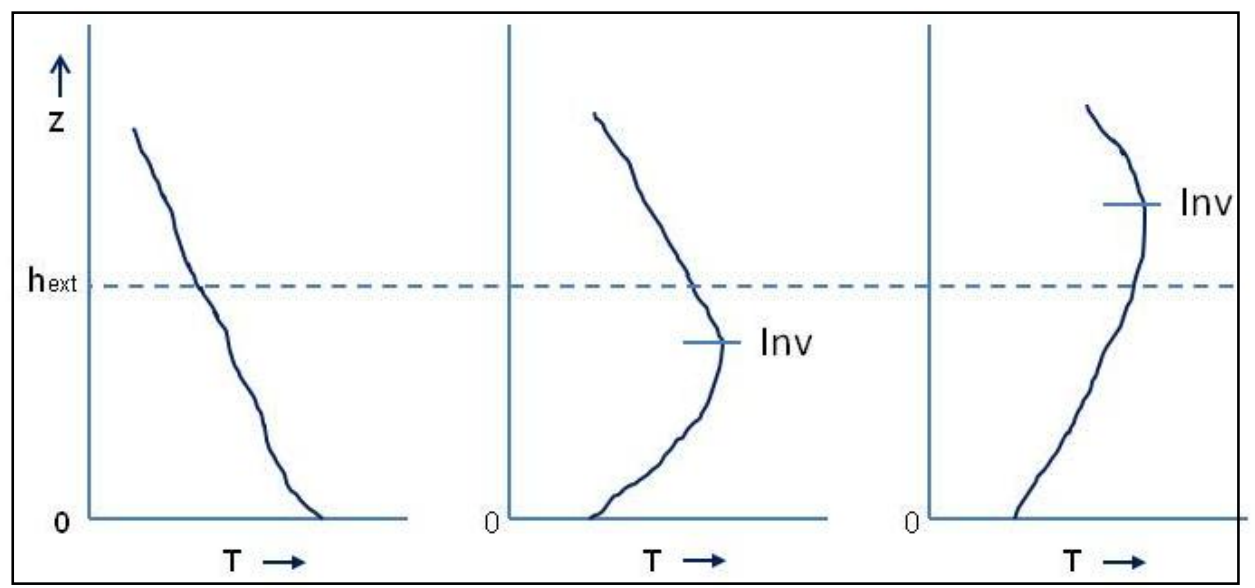

Figure 2. Three types of atmospheric temperature profiles accounted for by the extrapolation algorithm. From left to right: no inversion, top of inversion $\left(\mathrm{h}_{\mathrm{inv}}\right)$ below the extrapolation depth $\left(h_{\text {ext }}\right)$, and $h_{\text {inv }}$ above $h_{\text {ext }}$. Not shown are the cases of an elevated inversion or where $\mathrm{h}_{\mathrm{inv}}=\mathrm{h}_{\mathrm{ext}}$. If $\mathrm{h}_{\mathrm{inv}}=\mathrm{h}_{\mathrm{ext}}$, then the algorithm uses the same procedure as with $\mathrm{h}_{\mathrm{inv}}>\mathrm{h}_{\mathrm{ext}}$.

To find the inversion top, the extrapolation routine checks vertically adjacent points for the first occurrence of a lapse rate $(-\partial T / \partial z$, where $T=$ temperature and $z=$ height; $K / \mathrm{km})$ greater than the user-defined minimum inversion lapse rate $\left(\mathrm{L}_{\mathrm{invmin}}\right)$; this search starts at the surface and proceeds up to $\mathrm{h}_{\text {invmax }}$. Note that here a positive lapse rate indicates the common situation of temperature decreasing with height. Also, the minimum inversion lapse rate may be set by the user to a value greater than $0 \mathrm{~K} / \mathrm{km}$ in order to include within the inversion layer small positive lapse rates (e.g., $0.1 \mathrm{~K} / \mathrm{km}$ ) that represent nearly isothermal layers. The maximum inversion depth should be high enough to cover nearly all surface-based inversions; for the tests of this method, we used $1500 \mathrm{~m}$ above the nominal surface (i.e., $\mathrm{h}_{\text {invmax }}=1500 \mathrm{~m}$ ). If no lapse rates are less than the minimum inversion lapse rate $\left(\mathrm{L}_{\mathrm{invmin}}\right)$, the program defaults to the no inversion case. If a surface-based inversion is found, the routine computes the mean "inversion" lapse rate $\left(\mathrm{L}_{\text {inv }}\right)$ weighted by the layer thicknesses over all layers below the inversion top $\left(\mathrm{z}_{\mathrm{oldsfc}}+\mathrm{h}_{\mathrm{inv}}\right.$; layers where the lapse rate is less than or equal to the minimum inversion lapse rate). Afterwards, the routine computes the mean of the lapse rates of up to three layers above the inversion top ( $\mathrm{L}_{\text {aboveinv }}$ ) depending on how 
many layers are below the maximum inversion height $\left(\mathrm{h}_{\text {invmax }}\right.$; e.g., $\left.1500 \mathrm{~m}\right)$ or uses the lapse rate of the layer nearest the surface if there is no inversion. In this version of the program, if the inversion reaches the maximum inversion depth $\left(\mathrm{h}_{\text {invmax }}\right)$, which is possible but unlikely, the program does not compute an "above inversion" lapse rate $\left(\mathrm{L}_{\text {aboveinv }}\right)$. In that case, the routine prints a message to that effect and it exits. However, the user can set a higher value for $\mathrm{h}_{\text {invmax }}$ if there is a possibility of thicker surface-based inversions.

Both radiosonde soundings and profiles from model output can have super-adiabatic lapse rates as well as very strong inversions near the surface. Papers containing inversion data show the existence of strong negative lapse rates (Katurji and Zhong, 2012; and Whiteman et al., 2001). Certain radiosonde soundings as well as some model-generated profiles that were examined during this investigation exhibited very strong super-adiabatic or inversion lapse rates over short vertical distances (e.g., a temperature change of $0.5 \mathrm{~K}$ from the surface to $10 \mathrm{~m}$ above for a lapse rate of $-50 \mathrm{~K} / \mathrm{km}$ ). In order to prevent large-magnitude lapse rates from causing unrealistic extrapolated values of temperature, its value is bounded after each layer lapse rate is calculated. The maximum allowed positive lapse rate $\left(\mathrm{L}_{\max }\right)$ initially was set at $10 \mathrm{~K} / \mathrm{km}$, close to the adiabatic value of $9.8 \mathrm{~K} / \mathrm{km}$, and the most-negative allowed (inversion) lapse rate $\left(\mathrm{L}_{\min }\right)$ was initially set at $-15 \mathrm{~K} / \mathrm{km}$, which is less than the largest values found in the literature or in the observed data of this study. For example, Katurji and Zhong noted a negative temperature change of $10 \mathrm{~K}$ over $200 \mathrm{~m}(-50 \mathrm{~K} / \mathrm{km})$. However, over very short vertical extents (e.g., tens of meters) surface-based inversions often can exceed that amount under clear, dry, and calm conditions as seen in a number of radiosonde soundings examined for this report where on occasion the magnitude exceeded $-150 \mathrm{~K} / \mathrm{km}$. The values for the maximum magnitudes of the respective lapse rates may be changed by the user to improve the output as suggested by test results.

To more fully account for super-adiabatic lapse rates just above the surface, the difference between the input values for the surface and the first level above (radiosonde input) or between the surface and second level above (second Weather Research and Forecasting [WRF] input prognostic level) is added to the initially extrapolated surface value to help account for superadiabatic lapse rates near the surface (this source-dependent layer is henceforth referred to as $\mathrm{Z}_{\mathrm{oldsfc}+1: 2}$ to indicate that whether it refers to the first or second level above the surface depends on the data source). Frequently, the first data level above the surface (second data level in sounding) of a radiosonde is over $50 \mathrm{~m}$ above ground level (AGL), but for the WRF-based sounding for the WRF simulations used here it is around $12 \mathrm{~m}$ (the lowest level with prognostic output from the model). The second level above the surface in the WRF-based profile (third data level) in the data obtained for this report was often within a few meters of $45 \mathrm{~m}$, which often roughly compares with the first level above the surface in many radiosonde soundings. A similar procedure is used to help fully account for inversions since in the layer very near the surface 
(e.g., tens to perhaps a hundred meters) they may have very large magnitudes, as noted in the previous paragraph.

Surface wind observations are normally at $10 \mathrm{~m}$ AGL, but since, in the past, mesoscale models usually were not configured with a prognostic level near $10 \mathrm{~m}$ AGL, WRF includes a 10-m diagnostic wind to allow for better comparison with observations. However, in this case, since there is a prognostic level around 12.2 to $12.3 \mathrm{~m}$ AGL, this prognostic wind speed is preferred; the small height difference of about 2.2 to $2.3 \mathrm{~m}$ between it and the $10-\mathrm{m}$ level where observations are taken should not result in any major differences in wind speed and direction for the extrapolated profiles. Thus, rather than use the diagnostic values for $10 \mathrm{~m}$, we used the values for the lowest prognostic model level $(\sim 12 \mathrm{~m})$ as the surface wind speed and direction and consequent horizontal wind components for the computations. This procedure produced slightly better results for the set of WRF profiles that were examined herein versus using the $10-\mathrm{m}$ diagnostic values. Further comparisons of extrapolated profiles using WRF data with profiles based on nearly coincident radiosonde soundings should provide a more definitive answer with respect to wind accuracy. The procedure is not used with radiosonde sounding input. The radiosonde data may include surface station measurements for the surface, where the winds may be those for $2 \mathrm{~m}$ AGL versus $10 \mathrm{~m}$. The wind at $2 \mathrm{~m}$ AGL could be noticeably different than that at the second sounding level at perhaps $50 \mathrm{~m}$ AGL (first one above the surface), as was sometimes seen in the observations.

At this point, the algorithm divides into two sections, one for the case of no inversion and another for the situation of a surface-based inversion. If only an elevated inversion exists, the routine in its current form will not compute an inversion layer. However, the calculated mean lapse rate $\left(\mathrm{L}_{\mathrm{m}}\right.$; incorporating up to three layers) will at least partially account for an elevated inversion below the top of the uppermost layer used to calculate $\mathrm{L}_{\mathrm{m}}$.

\subsection{No Inversion}

The section of the algorithm, for the case where there is no surface-based inversion (i.e., zone of lapse rate less than the minimum inversion lapse rate $\mathrm{L}_{\text {invmin }}$ ), calculates a mean lapse rate and uses it to extrapolate temperature downward. Specifically, a lapse rate $\left(\mathrm{L}_{\mathrm{m}}\right)$ is computed for up to three layers nearest the old surface using the condition that any layer included in the mean must not extend above the maximum allowed inversion height (e.g., $1500 \mathrm{~m}$ ) in the input data (i.e., levels must not extend above $\mathrm{h}_{\text {invmax }}$ relative to the old surface).

The heights for each data level are moved upward by the extrapolation depth (in terms of AGL since the height in mean sea level [MSL] remains the same). For example, if the extrapolation depth is $200 \mathrm{~m}$, the former surface level is now at $200 \mathrm{~m}$ AGL and the height above is increased by $200 \mathrm{~m}$, etc. 
This mean lapse rate $\left(\mathrm{L}_{\mathrm{m}}\right)$ is then used to extrapolate temperature from the old surface $\left(\mathrm{z}_{\mathrm{oldsfc}}\right)$ to the new surface $\left(\mathrm{z}_{\text {newsfc }}\right)$, where "new" may refer to the surface defined by a finer-scale terrain database. For clarity, when referring to a quantity at a specific vertical location such as $\mathrm{z}_{\mathrm{x}}$ or $\mathrm{h}_{\mathrm{x}}$ (where $x$ may be "oldsfc", "newsfc", etc.), the subscript of the quantity includes only the " $x$ " and omits the " $z$ " or " $h$ ". For example, the temperature at the new surface is $T_{\text {newsfc }}$ rather than $\mathrm{T}_{z_{\text {newsfc }}}$. As noted above, to account for a super-adiabatic lapse rate near the surface, the user has the option to add the near-surface temperature difference (calculated between the input surface value $\left(\mathrm{T}_{\text {oldsfc }}\right)$ and that for the level immediately above for radiosonde data or the second level above (indicated by the subscript 1:2) in the case of WRF model data $\left(\mathrm{T}_{\text {oldsfc+1:2}}\right)$ to the initial extrapolated surface temperature. This procedure yields

$$
\mathrm{T}_{\text {newsfc }}=\mathrm{T}_{\text {oldsfc }}+\mathrm{h}_{\mathrm{ext}} * \mathrm{~L}_{\mathrm{m}}+\left(\mathrm{T}_{\mathrm{oldsfc}}-\mathrm{T}_{\text {oldsfc }+1: 2}\right)
$$

For relative humidity $(\mathrm{RH})$, the extrapolated value for the new surface is specified as the old surface value from the model or radiosonde. For the top of the extrapolation layer (the old surface; $\mathrm{z}_{\text {oldsfc }}$ ), the value is the mean of the old surface value and the value at the height immediately above from the input sounding or profile (i.e., $\mathrm{RH}_{\mathrm{oldsfc}}=0.5^{*}\left[\mathrm{RH}_{\mathrm{oldsfc}}+\mathrm{RH}_{\mathrm{oldsfc}+1}\right]$ ). This procedure avoids using the surface $\mathrm{RH}$ from the input as the value at the top of the extrapolation layer and, for the data examined herein, yields a more reasonable extrapolated value.

We use the standard hypsometric formula to compute the extrapolated pressure at the new surface $\left(\mathrm{p}_{\text {newsfc }}\right)$ using the pressure at the model or radiosonde surface $\left(\mathrm{p}_{\text {oldsfc }}\right)$; the mean of the temperature at the old surface and the value extrapolated down to the new surface $\left(0.5^{*}\left(\mathrm{~T}_{\text {oldsfc }}+\mathrm{T}_{\text {newsfc }}\right)\right)$; and the extrapolation depth $\left(\mathrm{h}_{\mathrm{ext}}\right)$.

For wind speed and direction, we set a specific height $\left(\mathrm{h}_{\max }\right)$ as the height above the surface at which we eliminate the influence of the surface wind. At another much smaller height $\left(\mathrm{h}_{\min }\right)$ away from the surface observation, we consider the wind to be the same as that at the surface observation; usually $\mathrm{h}_{\min }$ would not exceed $10 \mathrm{~m}$. This minimum value, $\mathrm{h}_{\min }$, is not the same as the minimum elevation difference used for determining the use of the extrapolation algorithm ( $h_{\text {extmin }}$ ), and these values should be chosen such that $h_{\min } \geq h_{\text {extmin }}$. To start out, we compute the horizontal wind components corresponding to the input wind speeds and directions from the old surface up through the two levels immediately above the extrapolation depth above the old surface (i.e., $\mathrm{z}_{\mathrm{oldsfc}}+\mathrm{h}_{\mathrm{ext}}$ ).

The wind speed and direction for the extrapolated or new surface is set equal to the values at the old surface (i.e., the surface of the input sounding or model-produced profile; e.g., $\mathrm{wspd}_{\text {newsfc }}=$ $\mathrm{wspd}_{\text {oldsfc }}$. The flowchart shown in figure 3 illustrates the procedures used to extrapolate wind. Where $h_{\text {ext }} \leq h_{\min }$, the wind speed and direction at the old surface are not changed, and therefore, are equal to those at the new surface. 


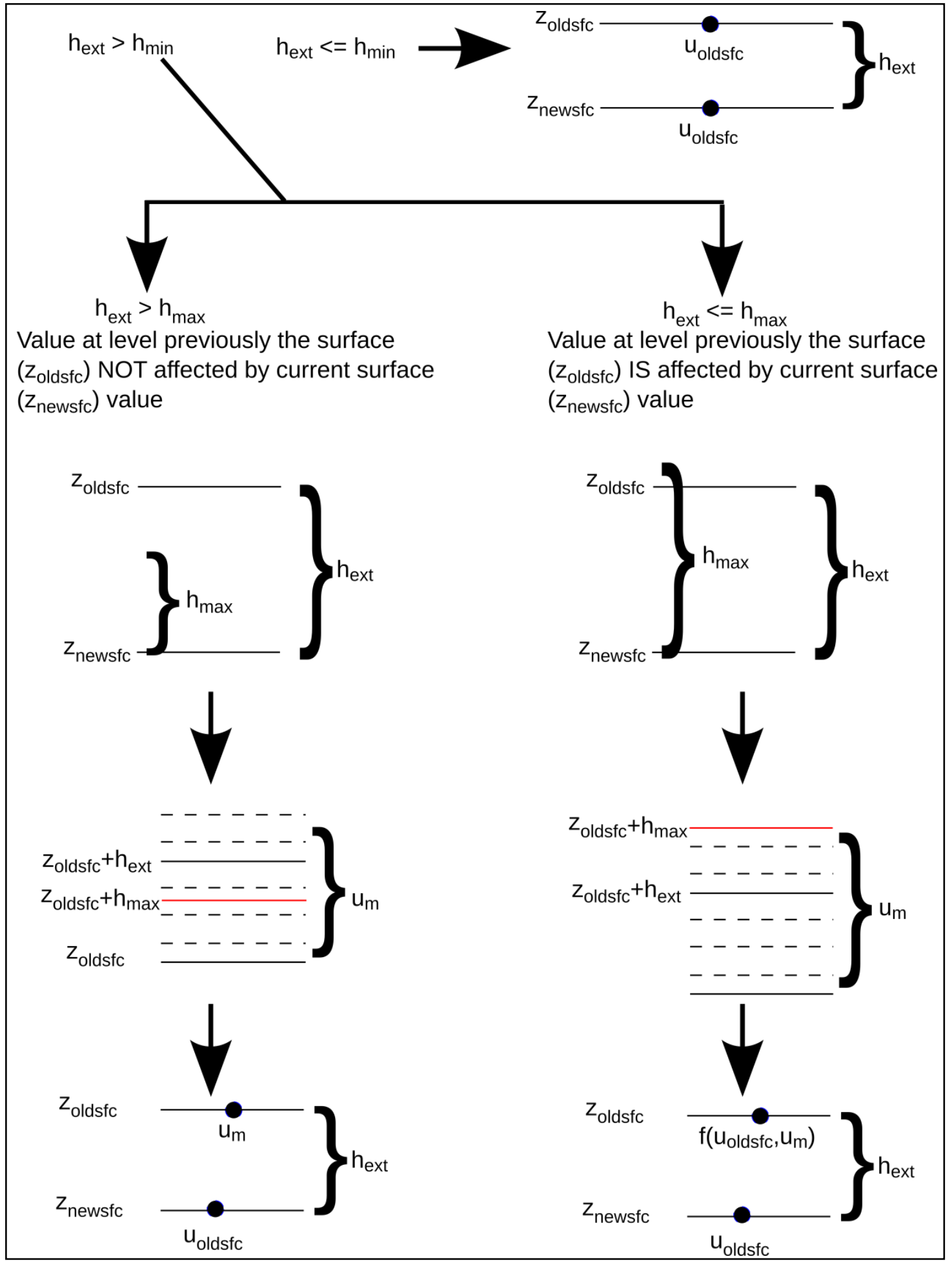

Figure 3. Schematic demonstrating the procedure used to extrapolate wind.

Where $h_{\text {ext }}>h_{\min }$, we first compute depth-coupled "layer values" of the input data components (u-layer, v-layer) where the components for a given data level represent the value over a layer 
extending from the midpoint of the adjacent layer below to the midpoint of the adjacent layer above. Figure 4 shows a schematic representation of this process. For example, the depthcoupled $\mathrm{u}$ component value for the $\mathrm{i}^{\text {th }}$ layer is as follows:

$$
\text { u-layer }{ }_{i}=\mathrm{u}_{\mathrm{i}} *\left(\left(\mathrm{~h}_{(\mathrm{i}+1)}+\mathrm{h}_{\mathrm{i}}\right) / 2-\left(\mathrm{h}_{(\mathrm{i})}+\mathrm{h}_{(\mathrm{i}-1)}\right) / 2\right) \text {. }
$$

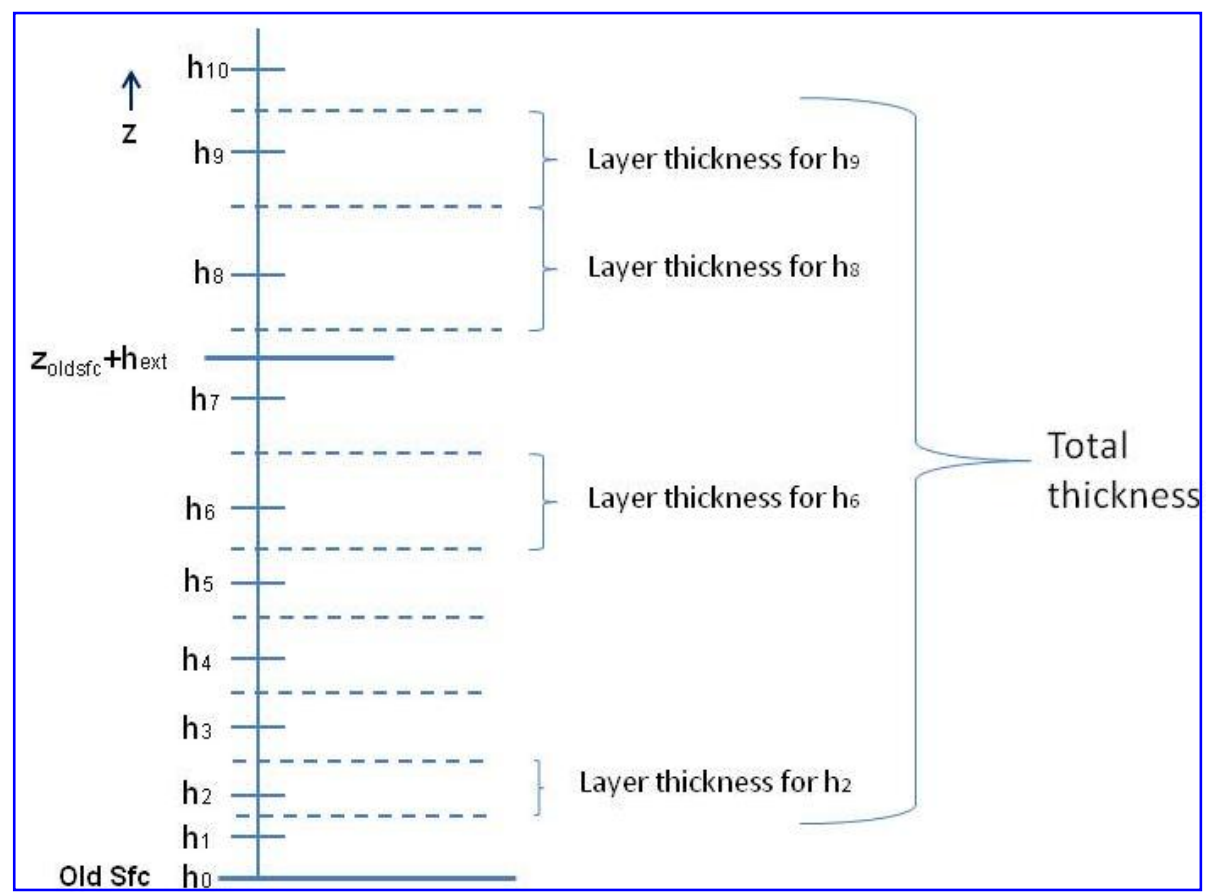

Figure 4. Schematic illustrating the computation of layer values for each height and the total mean value.

In figure 4 , the extrapolation depth is $\mathrm{h}_{\mathrm{ext}}$. Sample layer thicknesses are labeled, as is the total thickness. Each layer thickness is the difference between the midpoint height values above and below the specified height, and the depth-coupled variable (e.g., u-layer $r_{i}$ ) is the layer thickness multiplied by the value of the variable at the respective level. For example, the depth-coupled ucomponent for $\mathrm{h}_{6}\left(\mathrm{u}\right.$-layer $\left.{ }_{6}\right)$ is the $\mathrm{u}$-component at $\mathrm{h}_{6}$ multiplied by the difference between the heights defined by $\left(h_{7}+h_{6}\right) / 2$ and $\left(h_{6}+h_{5}\right) / 2$. The total mean value for $h_{2}$ through $h_{9}$ is the sum of the layer values times the respective layer thicknesses divided by the total thickness. In this example, the total thickness is defined by $\left(\mathrm{h}_{10}+\mathrm{h}_{9}\right) / 2-\left(\mathrm{h}_{2}+\mathrm{h}_{1}\right) / 2$. Also in this example we included the second height above $h_{\text {ext }}$ (implying $h_{\max } \geq h_{\text {ext }}$ ) and the second height above the surface (implying WRF input).

If the extrapolation depth $h_{\text {ext }}$ is greater than $h_{\min }$ and $h_{\text {ext }}$ is less than or equal to $h_{\max }$, then one should sum the layer values from $z_{\text {oldsfc }+1: 2}$ up through the second level above $h_{\text {ext }}$ above the old surface; the sum for the depth-coupled u-component is referred to as sum-u. Otherwise when $\mathrm{h}_{\max }<\mathrm{h}_{\text {ext }}$ above the old surface, the second level is not included in the calculation, that is, sum 
the components through the first level above $h_{\text {ext }}$ above the old surface. In this way, the impact of wind above $\mathrm{z}_{\text {oldsfc }}+\mathrm{h}_{\max }$ is reduced when the extrapolation depth above the old surface is above $\mathrm{h}_{\max }$. This procedure will tend to reduce, but not eliminate, the effect of wind at higher levels when the effect of the surface does not extend throughout the extrapolation layer, but will help account for upper level winds when the surface can affect winds throughout or above the extrapolation layer.

The updated value for the old surface is then the mean value $u_{m}$ as computed from the above sum of the depth-coupled u components (e.g., sum-u) divided by the total thickness (delta-h) of the layer from $\mathrm{z}_{\text {oldsfc }+1: 2}$ through the first or second level above $\mathrm{z}_{\mathrm{oldsfc}}+\mathrm{h}_{\mathrm{ext}}$ in the input data depending on the relative heights of $h_{\max }$ and $h_{\text {ext }}$ as noted in the previous paragraph. For example,

$$
\mathrm{u}_{\mathrm{m}}=\text { sum-u/delta-h, }
$$

where for the case where $h_{\text {ext }}$ is less than $h_{\max }$ above the old surface, delta-h $=\left(h_{(e x t+3)}+h_{(e x t+2)}\right) / 2$ $-\left(\mathrm{h}_{(2)}+\mathrm{h}_{(1)}\right) / 2$. A similar procedure is used for $\mathrm{v}_{\text {oldsfc }}$.

If the extrapolation depth is less than $h_{\max }\left(\right.$ and $h_{\text {ext }}>h_{\min }$ ), then the wind we calculate for the old surface should be influenced by the wind at the new surface. First, sum the layers as above and find the mean wind components $\mathrm{u}_{\mathrm{m}}$ and $\mathrm{v}_{\mathrm{m}}$. Next, linearly combine the mean wind with the wind at the new surface $u_{\text {newsfc }}$ based on the following ratio, which, in turn, is based on how the extrapolation depth $\left(h_{\text {ext }}\right)$ relates to the maximum depth to which surface winds should influence the winds $\left(\mathrm{h}_{\max }\right)$ :

$$
\text { ratio }=\left(\mathrm{h}_{\max }-\mathrm{h}_{\mathrm{ext}}\right) /\left(\mathrm{h}_{\max }-\mathrm{h}_{\min }\right) .
$$

The updated value at the old surface is computed as

$$
\mathrm{u}_{\mathrm{oldsfc}}=\mathrm{u}_{\mathrm{m}} *(1-\text { ratio })+\mathrm{u}_{\text {newsfc }} * \text { ratio, }
$$

and similarly for the $\mathrm{v}$ component using the same ratio.

The final step is the computation of wind speed and direction from the components. For wind speed, we used the standard formulation of the square root of the sum of the squares:

$$
\text { Wind speed }=\left((\mathrm{u})^{2}+(\mathrm{v})^{2}\right)^{0.5}
$$

For direction we used the 'C' function 'atan2' as follows:

$$
\text { Wind direction }=(2 \pi-\operatorname{atan} 2[\mathrm{u},-\mathrm{v}]) 180 / \pi \text {. }
$$

The direction using this function should not exceed $360^{\circ}$. 


\subsection{Inversion}

The computations for the situation of a surface-based zone of lapse rate less than the minimum lapse rate (i.e., inversion or near isothermal), have one or two extrapolated layers depending on whether (1) the extrapolation depth is greater than the inversion depth (i.e., $h_{\text {ext }}>h_{\text {inv }}$ ), or (2) the extrapolation depth is less than or equal to the inversion depth (i.e., $h_{\text {ext }} \leq h_{\text {inv }}$ ). For the case of the extrapolation depth less than that of the inversion, the same procedure is followed as for input without an inversion except that the mean lapse is now the inversion lapse rate. For both cases, the heights for each data level are moved upward by the extrapolation depth in terms of AGL as for the case of no inversion. Also, the algorithm attempts to eliminate the surface-based inversion from being expressed above the old surface height when the inversion height is less than the extrapolation depth. Therefore, input data levels within the inversion above the old (input) surface are removed. The first data level above the old surface (i.e., above the extrapolation depth) to appear in the output profile is the second level above the top of the inversion in the input data (input profile). This procedure ensures that there is no "reflection" of the surfacebased inversion above the extrapolation layer under this situation. This procedure is not used for an inversion height greater than or equal to the extrapolation depth since the algorithm essentially follows the one for no inversion, but with an inversion lapse rate.

\subsubsection{Extrapolation Depth Greater Than Inversion Depth}

In this case, the new profiles with the extrapolated layer will have two new data lines, one for the "new" surface $\left(z_{\text {newsfc }}\right)$ and one at the height of the top of the inversion above the new surface $\left(z_{\text {newsfc }}+h_{\text {inv }}\right)$. The calculations follow for the values for the new surface, the top of the inversion, and the modified values for the "old" surface, that is, at the top of the extrapolation layer ( $\mathrm{z}_{\text {oldsfc }}$ ). The height of the new surface value is set at zero (i.e., $z[0]=z_{\text {newsfc }}=0$ ), the height at data line one equals that at the top of the inversion (i.e., $\mathrm{z}[1]=\mathrm{h}_{\text {inv }}$ ), and the height for data line two, the old surface, is the extrapolation depth (i.e., $\mathrm{z}[2]=\mathrm{h}_{\text {ext }}$ ).

The temperature at the top of the extrapolation layer (old surface; $T_{\text {oldsfc }}$ ) is changed to take into account that the data line is no longer for the surface. The temperature at this height is set equal to the temperature at the extrapolation depth above the old surface (i.e., $\mathrm{T}_{\text {oldsfc+ext }}$ ). Since it is unlikely that there is a level in the input data exactly at the extrapolation depth above the old surface, we must first find this value via linear interpolation between the levels immediately above $\left(\mathrm{T}_{\text {oldsfc+ext+1 }}\right)$ and immediately below this layer $\left(\mathrm{T}_{\text {oldsfc+ext-1 }}\right)$.

The above-inversion lapse rate $\left(\mathrm{L}_{\text {aboveinv }}=\mathrm{L}_{\mathrm{m}}\right.$ from the top of the inversion vs. from the surface) is then used to extrapolate downward from the old surface to the inversion height above the new surface:

$$
\mathrm{T}_{\text {newsfc }+ \text { inv }}=\mathrm{T}_{\text {oldsfc }}+\left(\mathrm{z}_{\text {oldsfc }}-\left[\mathrm{z}_{\text {newsfc }}+\mathrm{h}_{\text {inv }}\right]\right) * \mathrm{~L}_{\text {aboveinv }}
$$


The temperature at the new surface is calculated by using the inversion lapse rate $\left(\mathrm{L}_{\text {inv }}\right)$ to extrapolate downward from temperature at the top of the inversion ( $\left.\mathrm{T}_{\text {newsfc+inv }}\right)$. In addition, we help account for strong inversions in a manner similar to the super-adiabatic correction, except that we subtract the difference in temperature between that at the level immediately above the surface and at the surface when using radiosonde data. When using WRF output profiles, we substitute the second level above the surface for the first one for reasons given in section 2.1:

$$
\mathrm{T}_{\text {newsfc }}=\mathrm{T}_{\text {newsfc }+ \text { inv }}+\mathrm{h}_{\text {inv }} * \mathrm{~L}_{\mathrm{inv}}-\left(\mathrm{T}_{\text {oldsfc }+1: 2-\mathrm{T}_{\text {oldsfc }}}\right)
$$

Pressure is calculated using the hypsometric equation for the top of the inversion using the pressure at the old surface (= pressure at top of extrapolation layer; $p_{\text {oldsfc }}$ ), the height difference between the old surface and the top of the inversion $\left(\mathrm{z}_{\text {oldsfc }}-\left[\mathrm{z}_{\text {newsfc }}+\mathrm{h}_{\text {inv }}\right]\right)$, and the mean of the new temperatures at those heights. The calculated pressure at the top of the inversion, the height difference between the top of the inversion and new surface (effectively the inversion height), and the mean of the respective temperatures are then used to extrapolate pressure down to the new surface.

For $\mathrm{RH}$, the value at the old surface becomes the value at the new one. The value at the top of the extrapolation layer $\left(\mathrm{RH}_{\text {oldsfc }}\right)$ is taken as the value at the level just above the inversion in the input profile (i.e., $\mathrm{RH}_{\text {oldsfc }}=\mathrm{RH}_{\text {oldsfc+inv }+1}$ ). For the level at the top of the inversion, the value from the model or sounding at the level just above the inversion is averaged with the old surface value (i.e., $\mathrm{RH}_{\text {newsfc+inv }}=0.5 *\left[\mathrm{RH}_{\mathrm{oldsfc}+\mathrm{inv}+1}+\mathrm{RH}_{\mathrm{oldsfc}}\right]$ ).

Wind speed and direction are handled in the same manner as for the case of no inversion.

\subsubsection{Extrapolation Depth Less Than or Equal to Inversion Depth}

In this case, the new profiles with the extrapolated layer will have one new data line, one for the "new" surface since the extrapolation depth does not exceed the inversion depth. The calculations follow for the values for the new surface and the modified values for the "old" surface, that is, at the top of the extrapolation layer.

The temperature calculations follow the same procedure as for the case of extrapolation when there is no inversion (section 2.1), except that we substitute the inversion lapse rate for the lapse rate and, of course, there is no correction for super-adiabatic lapse rates. As for the surface temperature in 2.2.1 (inversion height less than extrapolation depth), we help account for strong inversions by subtracting the difference in temperature between that at the level immediately above the surface and at the surface when using radiosonde data. When using WRF output profiles, we substitute the second level above the surface for the first one for reasons given in section 2.1. This procedure yields

$$
\mathrm{T}_{\text {newsfc }}=\mathrm{T}_{\text {oldsfc }}+\mathrm{h}_{\text {ext }} * \mathrm{~L}_{\mathrm{inv}}-\left(\mathrm{T}_{\text {oldsfc }+1: 2^{-}} \mathrm{T}_{\text {oldsfc }}\right)
$$


The pressure at the top of the extrapolation layer is that of the former surface. The new surface pressure is computed using the hypsometric formula as in section 2.1.

The RH for the surface is the value for the surface from the input data. The value for the top of the extrapolation layer is the average of the value immediately above the surface and the surface value from the input data (i.e., $\mathrm{RH}_{\text {oldsfc }}=0.5^{*}\left[\mathrm{RH}_{\mathrm{oldsfc}+1}+\mathrm{RH}_{\mathrm{oldsfc}}\right]$ ).

Wind speed and direction are handled in the same manner as for the case of no inversion.

\section{Sample Output}

We present samples of input and output for the three cases noted above: no inversion, inversion height less than the extrapolation depth (i.e., $h_{\text {inv }}<h_{\text {ext }}$ ), and inversion height equal to or greater than the extrapolation depth (i.e., $\mathrm{h}_{\mathrm{inv}} \geq \mathrm{h}_{\mathrm{ext}}$ ). To save space, only the first several lines of data are shown (i.e., the first several data points starting at the surface). We apply the extrapolation techniques described in the previous sections to the WRF output in order to extrapolate downwards for comparison to rawinsondes or other WRF output. For the radiosonde cases, we extracted soundings from the University of Wyoming Web site (http://www.weather.uwyo.edu/). The WRF output files were generated locally at ARL. The extrapolated values may be compared with the traditional method of using a standard atmosphere to extrapolate down to the new surface, that is, for example, a standard lapse rate for temperature (i.e., $0.0065 \mathrm{~K} / \mathrm{m}$ ) and using the old surface values for wind throughout the extrapolation depth down to the new surface.

WRF v3.4.1 with 9-, 3-, and 1-km horizontal grid spacing domains was used to generate the WRF output for three cases. For one case, the forecast was centered in southern California and was integrated from 12 universal time coordinated (UTC) on 9 February 2012 through 12 UTC on 10 February 2012. Another forecast was centered over Grand Junction (GJT), CO, and was integrated from 12 UTC on 13 January 2013 for $24 \mathrm{~h}$. The third forecast was centered over Prince George (ZXS), British Columbia (BC), Canada, and was integrated from 12 UTC on 11 January 2013 for $24 \mathrm{~h}$. The initial conditions and boundary conditions were derived from Global Forecast System (GFS) 0.5-degree horizontal grid spacing output. Where available, GFS snow fields were replaced with 1-km snow fields from the National Weather Service's National Operational Hydrologic Remote Sensing Center (NOHRSC) Snow Data Assimilation System (SNODAS) (National Operational Hydrologic Remote Sensing Center, 2004). A sea surface temperature product with higher resolution than the GFS output is produced by the National Centers for Environmental Prediction, Marine Modeling and Analysis Branch, called the Real Time Global Sea Surface Temperature (Gemmill et al., 2007), which has $1 / 12^{\text {th }}$-degree horizontal grid spacing and was used to specify sea surface temperatures for the southern California case (this product was not available at the time of the simulations for the other two cases due to long- 
duration computer failure at the data provider's location). No data assimilation was used for these forecasts.

The Mellor-Yamada-Janjić scheme (MYJ) is used to parameterize the atmospheric boundary layer. As in Lee et al. (2012) and Reen et al. (2014), the background turbulent kinetic energy is decreased to better simulate conditions with low turbulent kinetic energy and the atmospheric boundary layer depth diagnosis is altered. The WRF single-moment 5-class microphysics parameterization and the Kain-Fritsch cumulus parameterization are used. For radiation, the Rapid Radiative Transfer Model is used for longwave and the Dudhia scheme for shortwave. The Noah land surface model is used to represent land surface processes.

Here we looked at WRF-generated profiles for locations close to, but not coincident with, radiosonde sites. We used the GJT, CO, World Meteorological Organization (WMO) radiosonde site and ZXS Canadian WMO site. GJT is located west of the Rocky Mountains at 39.11N latitude and 108.53W longitude at an elevation of $1475 \mathrm{~m}$. ZXS lies to the east of the Canadian Rocky Mountains at $53.90 \mathrm{~N}$ and $122.80 \mathrm{~W}$ at an elevation of $601 \mathrm{~m}$. Those sites have (1) regular radiosonde soundings every $12 \mathrm{~h}$ and (2) are located close to higher terrain. WRF model grid points not coincident with the radiosondes were used to extract the WRF profiles since the WRF grid points nominally closest to those radiosonde sites had lower elevations than the observations, which would preclude using extrapolations. For the WRF profiles derived from the 9-km data, the grid points closest to the sites had lower and nearly equal elevations than the GJT and ZXS sites, respectively. In order to choose grid points with elevations higher than the observations so that extrapolation methods could be tested, for the GJT 3-km data, we had to use data two grid points to the north, and for the 1-km data, four grid points to the north versus one point to the north for the 9-km data. Finer-resolution WRF data (i.e., 3- and 1-km horizontal grid spacing) for the ZXS case are not shown here. We also briefly examined data for the Anchorage, AK (PANC), radiosonde site for the case of the inversion height equal to or greater than the extrapolation depth (i.e., $\mathrm{h}_{\mathrm{inv}} \geq \mathrm{h}_{\mathrm{ext}}$ ). PANC lies at the end of a broad inlet extending northward from the Gulf of Alaska at $61.16 \mathrm{~N}$ and $151.01 \mathrm{~W}$ at an elevation of $40 \mathrm{~m}$.

An important consideration is that differences between the extrapolated WRF values and the radiosonde values are not necessarily due solely to errors in the extrapolation. One potential contributor to these differences are errors in the model forecast - the model grid cells from which data are obtained for the extrapolation may not match the conditions averaged over these grid cells in the actual atmosphere. Another potential contributor is representativeness error-the model forecast - is for a grid cell covering some volume at a specific time, whereas the radiosonde is a series of approximately point measurements at specific times that likely do not exactly match the model forecast time (for example, temperature, pressure, and humidity may be averages over a slant path of a few meters; wind values for a global positioning system (GPS) sonde may consist of mean values over slant paths on the order of several tens of meters). Also, 
for comparisons in this report, the closest model grid point to the observation was often not used, because a grid point was needed with a higher surface elevation than the observation in order to test the extrapolation. Partly because of these issues, it can be difficult to determine if an extrapolation technique is better than the standard technique, since weaknesses of an extrapolation technique may compensate for errors in the model forecast or differences caused by extracting WRF output at a location not coincident with the rawinsonde.

The goal of the extrapolation algorithm is to provide the best estimate of the profile down to the actual surface. However, it may be difficult to determine the best profile given only the model profile down to the model surface. Changing the height of the terrain may result in effects that are more complex than can be accounted for by simply looking at a profile at a single time and location. For example, changing the height of the terrain may affect the flow patterns in the area. If the actual terrain height at a location is lower than the model assumes when making its forecast, the real world may develop an inversion from cold air pooling that would not have formed with the terrain elevation that the model used.

Therefore, in the context of this report, the goal is to develop and test whether an extrapolation method on average performs better than the standard methodology, while recognizing that it may be difficult to determine the exact sources of mismatches between the extrapolated values and observations.

\subsection{No Inversion}

In this case, the sounding has no surface-based inversion. Two samples are provided. In the first one, we compare a sample of WRF profiles with a close to coincident radiosonde sounding. In the second, we compare WRF-derived atmospheric profiles at different grid resolutions. In the comparisons, $\mathrm{h}_{\max }$ was set at $400 \mathrm{~m}$ unless otherwise stated.

\subsubsection{Comparison with Radiosonde}

Here we look at WRF-generated profiles for a location close to, but not coincident with, the GJT WMO radiosonde site. The GJT sounding for 00 UTC on 14 February 2013 did not have a surface-based inversion (table 1). However, the WRF output at that time displayed an inversion with a small decrease in temperature in the lowest two levels, and therefore, would not be appropriate for a non-inversion comparison. Consequently, we used the output closest in time to the nominal radiosonde time that did not have an inversion, that is, the WRF output for 23 UTC on 13 February 2013 (table 2). Also, a common practice is to launch the balloon before the nominal time (e.g., a half hour before). In that way, the radiosonde is not too far from the sounding midpoint by the nominal time. The standard procedure is as follows: "The actual release time of the regular radiosonde soundings shall fall within the time interval from 45 minutes before to the scheduled time of the observation" (OFCM, 1997). Consequently, the 
earlier time (23 UTC) actually may be closer to the radiosonde observations for the lowest levels. Table 3 shows the extrapolated profiles.

Table 1. Radiosonde sounding for GJT on 14 January 2013 or the 00 UTC sounding. The latitude and longitude are $39.11 \mathrm{~N}$ and $108.53 \mathrm{~W}$, respectively, with an elevation of $1475 \mathrm{~m}$, showing data levels from the surface through $750 \mathrm{hPa}$.

\begin{tabular}{|c|c|c|c|c|c|}
\hline HGHT & PRES & TEMP & RELH & SPD & DIR \\
\hline m MSL & hPa & ${ }^{\circ} \mathbf{C}$ & \% & knot & deg \\
\hline 2438 & 750.0 & -16.7 & 56 & 11 & 280 \\
\hline 2171 & 777.0 & -14.7 & 60 & 9 & 289 \\
\hline 2134 & 780.8 & -14.4 & 59 & 9 & 290 \\
\hline 1829 & 812.7 & -12.2 & 54 & 7 & 330 \\
\hline 1715 & 825.0 & -11.3 & 52 & 7 & 337 \\
\hline 1485 & 850.0 & -10.3 & 57 & 7 & 350 \\
\hline 1475 & 851.0 & -10.1 & 75 & 7 & 355 \\
\hline
\end{tabular}

Note: Height (HGHT) is in $\mathrm{m}$ MSL, pressure (PRES) in $\mathrm{hPa}(\mathrm{mb})$, temperature (TEMP) in ${ }^{\circ} \mathrm{C}$, relative humidity (RELH) in percent, wind speed (SPD) in knots and wind direction (DIR) in degrees.

Table 2. Profiles generated from WRF output for a location near GJT at latitude $39.17 \mathrm{~N}$ and $108.49 \mathrm{~W}$ at $23 \mathrm{UTC}$ on 13 January 2013. The grid resolution was $1 \mathrm{~km}$ and the elevation from the terrain database to the nearest meter was $1615 \mathrm{~m}$ MSL.

\begin{tabular}{|c|c|c|c|c|c|}
\hline HGHT & PRES & TEMP & RELH & SPD & DIR \\
\hline m MSL & hPa & ${ }^{\circ} \mathbf{C}$ & \% & knot & deg \\
\hline 1947.1 & 800.1 & -12.4 & 71 & 3.9 & 324 \\
\hline 1876.1 & 807.6 & -11.9 & 77 & 3.9 & 329 \\
\hline 1809.2 & 814.6 & -11.4 & 86 & 4.1 & 323 \\
\hline 1750.2 & 820.9 & -10.9 & 89 & 4.3 & 315 \\
\hline 1698.8 & 826.4 & -10.4 & 86 & 4.5 & 309 \\
\hline 1654.9 & 831.1 & -10.0 & 85 & 4.3 & 306 \\
\hline 1625.7 & 834.3 & -10.0 & 88 & 3.0 & 310 \\
\hline 1614.8 & 835.7 & -9.8 & 86 & 3.3 & 310 \\
\hline
\end{tabular}

Note: Height (HGHT) is in m MSL, pressure (PRES) in hPa, temperature (TEMP) in ${ }^{\circ} \mathrm{C}$, relative humidity (RELH) in percent, wind speed (SPD) in knots, and wind direction (DIR) in degrees. 
Table 3. Extrapolated profiles generated from 1-km WRF output using our method for the same location and time as table 2. The variables are the same as in table 2, except that HGHT is in AGL and MSL rather than just MSL. The extrapolation depth was $140 \mathrm{~m}$. The levels where the extrapolated profile differs from the original profile in table 2 are highlighted.

\begin{tabular}{|c|c|c|c|c|c|c|}
\hline HGHT & HGHT & PRES & TEMP & RELH & SPD & DIR \\
\hline m AGL & m MSL & hPa & ${ }^{\circ} \mathbf{C}$ & \% & knot & deg \\
\hline 472.3 & 1947.1 & 800.1 & -12.4 & 71 & 3.9 & 324 \\
\hline 401.3 & 1876.1 & 807.6 & -11.9 & 77 & 3.9 & 329 \\
\hline 334.4 & 1809.2 & 814.6 & -11.4 & 86 & 4.1 & 323 \\
\hline 275.3 & 1750.1 & 820.9 & -10.9 & 89 & 4.3 & 315 \\
\hline 223.9 & 1698.7 & 826.4 & -10.4 & 86 & 4.4 & 309 \\
\hline 180.1 & 1654.9 & 831.1 & -10.0 & 85 & 4.3 & 306 \\
\hline 150.9 & 1625.7 & 834.3 & -10.0 & 88 & 3.0 & 310 \\
\hline 140.0 & 1614.8 & 835.7 & -9.8 & 87 & 3.4 & 312 \\
\hline 0.0 & 1474.8 & 851.0 & -9.3 & 86 & 3.0 & 310 \\
\hline
\end{tabular}

In this example, the extrapolated surface temperature was about $0.8 \mathrm{~K}$ higher than the surface temperature from the radiosonde, but still about $0.5 \mathrm{~K}$ better than the standard method (which yielded a temperature of about $-8.8^{\circ} \mathrm{C}$ ) that uses the standard atmosphere's lapse rate of $0.0065 \mathrm{~K} \mathrm{~m}^{-1}$ in order to extrapolate downward to the surface observation (figure 5). In this specific case, the observed surface temperature in the radiosonde data was lower than in the WRF output even though no inversion was present. Consequently, the original WRF-based surface temperature at the old surface was a better estimate than the extrapolated value, but this situation may not occur at other times and places (see next paragraph). The wind speed at the new surface was slightly closer to that from the radiosonde using the standard method of keeping the "old" surface wind constant throughout the extrapolation depth (by $0.3 \mathrm{kts}$ ). However, the wind speed at the old surface was slightly closer with the new method (by $0.1 \mathrm{kts}$ ), but they were both still too low as one could expect since the model wind speeds at and above the surface were too low. The wind directions were comparable relative to the radiosonde since the wind changed little with height. 
(a)

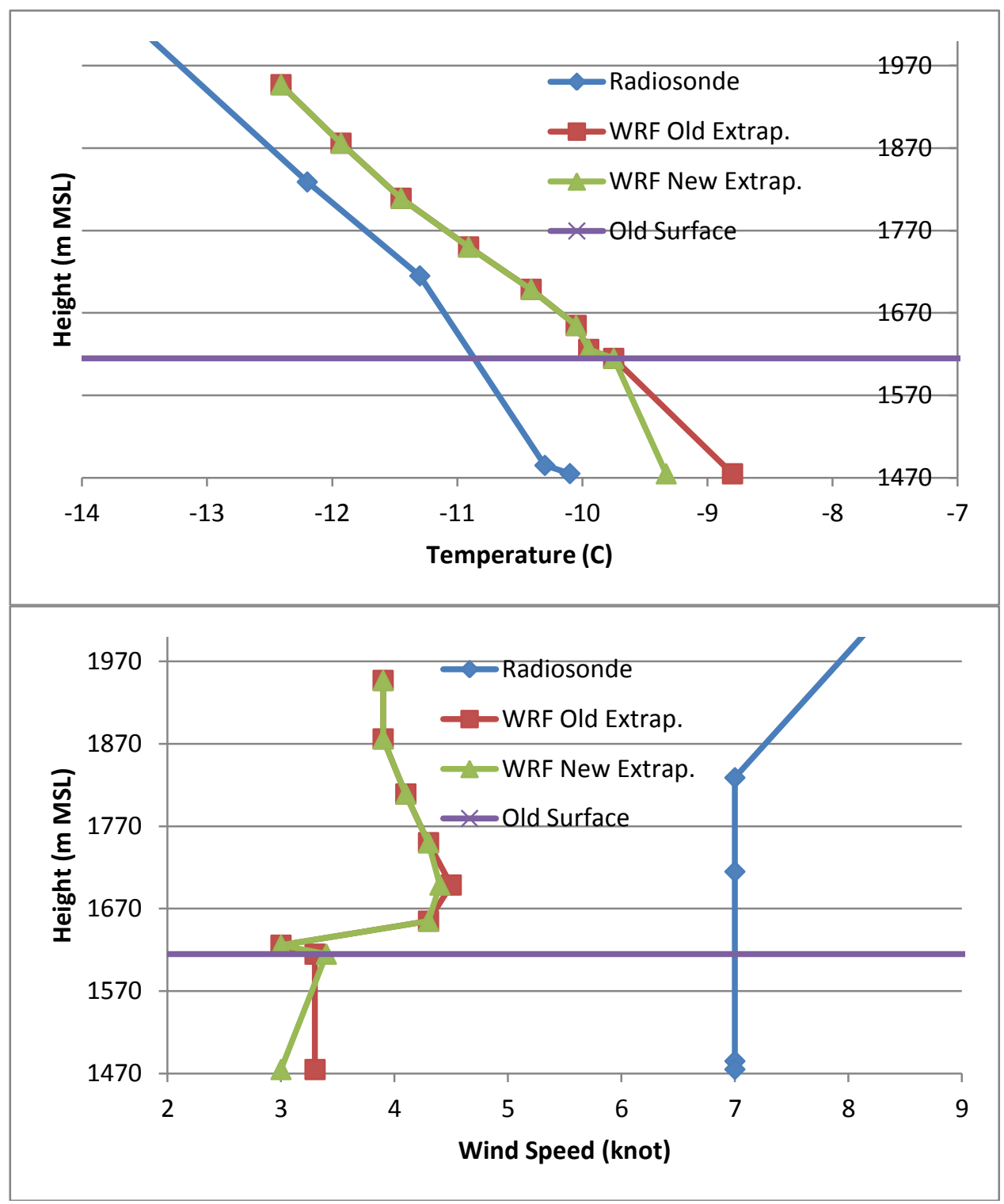

Figure 5. Profiles comparing the 00 UTC 14 January 2013 GJT radiosonde to 1-km WRF data from 23 UTC extended from the "old surface" to the radiosonde surface using the standard extrapolation and the extrapolation method proposed here for (a) temperature and (b) wind speed.

Overall, the other cases examined show that the extrapolation methodology described herein compared to the commonly used extrapolation method results in extrapolated WRF temperatures that somewhat more closely match radiosonde values, but very little or no improvement with respect to wind. The surface pressures derived from this method came very close to the radiosonde values, as did the standard method. These outcomes suggest that the method of this report will provide better values only if the lapse rate is not near the lapse rate of the standard atmosphere, and the wind direction and speed changes with height near the surface. In other words, unsurprisingly, the new method will only be an improvement on the standard method in 
cases where the atmospheric lapse deviates from that of the standard atmosphere and the wind varies significantly near the surface.

\subsubsection{WRF Inter-Comparisons}

Tables 4-6 present: (1) profiles from 3-km WRF output (table 4), (2) the extrapolated sounding using a 132-m extrapolation depth (table 5), and (3) profiles from 1-km output for the same location and time (table 6). The $132 \mathrm{~m}$ height is the difference in the terrain database elevations between the coarser $(3 \mathrm{~km})$ WRF run (higher) and the finer $(1 \mathrm{~km})$ run (lower).

Note that the height in table 5 is listed in both AGL and above MSL. The levels where the extrapolated profile in table 5 differs from the original profile in table 4 are highlighted.

Table 4. Profiles generated from WRF output for a site centered on southern California, latitude $33.264 \mathrm{~N}$ and $116.826 \mathrm{~W}$, at $22 \mathrm{UTC}$ on 09 February 2013. The grid resolution was $3 \mathrm{~km}$.

\begin{tabular}{|c|c|c|c|c|c|}
\hline HGHT & PRES & TEMP & RELH & SPD & DIR \\
\hline m MSL & hPa & ${ }^{\circ} \mathbf{C}$ & \% & knot & deg \\
\hline 1248.0 & 881.4 & 16.1 & 33 & 4.5 & 268 \\
\hline 1173.3 & 889.2 & 16.8 & 32 & 4.7 & 266 \\
\hline 1107.3 & 896.1 & 17.5 & 31 & 4.8 & 265 \\
\hline 1049.8 & 902.2 & 18.2 & 30 & 4.8 & 264 \\
\hline 1000.8 & 907.3 & 18.8 & 29 & 4.6 & 262 \\
\hline 968.1 & 910.8 & 19.5 & 29 & 3.8 & 261 \\
\hline 955.9 & 912.0 & 20.4 & 29 & 4.9 & 261 \\
\hline
\end{tabular}

Note: Height (HGHT) is in m MSL, pressure (PRES) in hPa, temperature (TEMP) in ${ }^{\circ} \mathrm{C}$, relative humidity (RELH) in percent, wind speed (SPD) in knots, and wind direction (DIR) in degrees.

Table 5. Extrapolated profiles generated from the WRF output of table 4. The grid resolution was $3 \mathrm{~km}$. The extrapolation depth was $132 \mathrm{~m}$. Levels with values that differ from table 4 are highlighted.

\begin{tabular}{|c|c|c|c|c|c|c|}
\hline HGHT & HGHT & PRES & TEMP & RELH & SPD & DIR \\
\hline m AGL & m MSL & hPa & ${ }^{\circ}$ C & \% & knot & deg \\
\hline 434.1 & 1258.0 & 881.4 & 16.1 & 33 & 4.5 & 268 \\
\hline 349.4 & 1173.3 & 889.2 & 16.8 & 32 & 4.7 & 266 \\
\hline 283.4 & 1107.3 & 896.1 & 17.5 & 31 & 4.8 & 265 \\
\hline 225.9 & 1049.8 & 902.2 & 18.2 & 30 & 4.8 & 264 \\
\hline 176.9 & 1000.8 & 907.3 & 18.8 & 29 & 4.6 & 262 \\
\hline 144.2 & 968.1 & 910.8 & 19.5 & 29 & 3.8 & 261 \\
\hline 132.0 & 955.9 & 912.0 & 20.4 & 29 & 4.1 & 262 \\
\hline 0.0 & 823.9 & 926.1 & 21.6 & 29 & 3.8 & 261 \\
\hline
\end{tabular}


Table 6. Profiles generated from WRF output for the same location and time as in tables 4 and 5, but for a grid resolution of $1 \mathrm{~km}$.

\begin{tabular}{|c|c|c|c|c|c|}
\hline HGHT & PRES & TEMP & RELH & SPD & DIR \\
\hline m MSL & hPa & ${ }^{\circ} \mathbf{C}$ & \% & knot & deg \\
\hline 1196.8 & 886.8 & 16.4 & 28 & 3.72 & 281 \\
\hline 1117.2 & 895.2 & 17.1 & 27 & 4.20 & 279 \\
\hline 1042.2 & 903.1 & 17.9 & 27 & 4.33 & 279 \\
\hline 976.0 & 910.1 & 18.6 & 26 & 4.35 & 279 \\
\hline 918.3 & 916.2 & 19.2 & 25 & 4.30 & 280 \\
\hline 869.0 & 921.5 & 19.8 & 25 & 4.08 & 281 \\
\hline 836.3 & 925.0 & 20.4 & 25 & 3.37 & 284 \\
\hline 824.0 & 926.3 & 21.2 & 26 & 4.35 & 284 \\
\hline
\end{tabular}

The near-surface profiles from the two data sources are shown in figure 6 . The surface temperature from the coarser grid extrapolated down to the surface of the finer grid (table 5) is $0.4 \mathrm{~K}$ warmer than the surface temperature predicted by the finer grid (table 6). Compare this to the un-extrapolated surface temperature from the coarser grid WRF output (table 4) being $0.8 \mathrm{~K}$ too cold relative to the surface temperature of the finer grid (table 6). The wind speeds on the finer grid (table 6) nearer, but not at, the surface are fairly close to that of tables 4 and 5 . The wind speeds shown for the surface (10 m AGL) is approximated using WRF output from the lowest model level, here at $12.23 \mathrm{~m}$ AGL (table 4). The extrapolation method introduced in this report uses the lowest model level as the surface value as it is most likely to be more accurate (here a difference in height of only $2.23 \mathrm{~m}$ ). The wind directions at the extrapolation depth and the surface are based on the coarser grid data and are similar. The extrapolated pressure for the surface and the pressure from the fine domain (1-km horizontal grid spacing) differ by only about $0.2 \mathrm{hPa}$. However, when the lapse rate is close to the standard lapse rate, the current method based on the standard lapse rate can produce good results when there is no inversion. In this case, it led to a surface temperature that was about $0.1 \mathrm{~K}$ warmer than that from the finerresolution data and $0.3 \mathrm{~K}$ better than the extrapolation method proposed in this report. Also the wind directions showed almost no change in the lowest few levels so that using the surface value for direction was about the same. The extrapolated wind speeds showed a very modest improvement in fit to the finer grid relative to the standard extrapolation method, but the change with height in the coarser profile was only about $1 \mathrm{~ms}^{-1}$. 


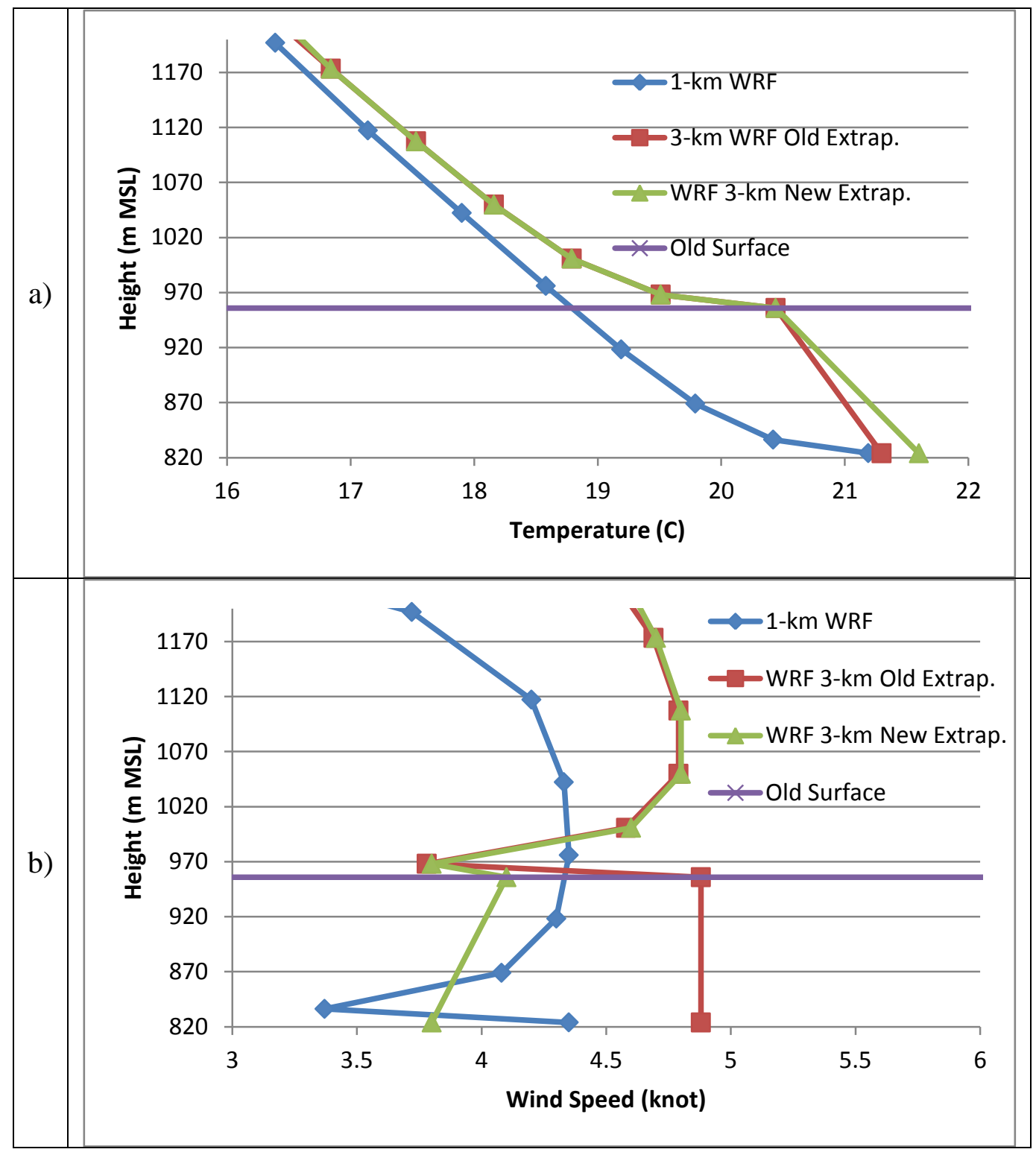

Figure 6. Profiles comparing 1-km WRF data and 3-km WRF data extended from the "old surface" to the radiosonde surface using the standard extrapolation and extended using the extrapolation method proposed here at a site in an area centered on southern California, latitude $33.264 \mathrm{~N}$ and $116.826 \mathrm{~W}$, at 22 UTC on 09 February 2013 for (a) temperature and (b) wind speed.

An important consideration for this comparison is that the terrain databases are different for the different model grid resolutions and the coarser one will smooth out features that appear in the finer terrain. That could lead to different treatment of wind and possibly temperature near the surface, thereby complicating any comparison. Also, the different physics packages may be used depending on the grid resolution. For example, in the WRF forecasts used here, the 9-km domain used a cumulus parameterization while the other two domains did not. That could change the forecasted meteorological variables without any change in the surface elevation. 
Where the extrapolation depth is less than the minimum height $\left(\mathrm{h}_{\mathrm{min}}\right)$, the values for the new surface and at the extrapolation depth are those for the old one, that is, they are the same.

Normally, we set $\mathrm{h}_{\min } \leq 10 \mathrm{~m}$ and frequently have a value $<5 \mathrm{~m}$. Note that the standard height for "surface" wind is $10 \mathrm{~m}$, and that for temperature is $2 \mathrm{~m}$. The height for pressure is either $2 \mathrm{~m}$ or the actual surface $(0 \mathrm{~m})$. Examples for the case of the extrapolation depth $<\mathrm{h}_{\min }$ are not shown.

\subsection{Surface-Based Inversion}

In this section, we look at profiles or soundings that have surface-based inversions. For the situation of the inversion height lower than the extrapolation depth, we examine profiles from the WRF output and compare them with radiosonde soundings. As for the case of no inversion, no examples are shown for extrapolation depth $<\mathrm{h}_{\min }$.

\subsubsection{Extrapolation Depth Greater Than Inversion Depth}

Here we look at WRF-generated profiles for locations very near the GJT WMO radiosonde site that was used for the non-inversion case, but with the 12 UTC sounding for 14 January 2013 (table 7). The surface-based inversion extended up to $1553 \mathrm{~m}$ MSL or $78 \mathrm{~m}$ AGL (station elevation $=1475 \mathrm{~m} \mathrm{MSL}$ ). The terrain database elevations for nearby grid points where the surface was above the GJT site are listed in the WRF data table captions for that location. In these cases, the extrapolation depth is the difference from the database elevations to that of the radiosonde site. Table 7 shows the lower part of the GJT sounding for the aforementioned day and time. Certain variables such as potential temperature are not included in the table.

Table 7. Radiosonde sounding for GJT on 14 January 2013 at 1200 UTC. The latitude and longitude are $39.11 \mathrm{~N}$ and $108.53 \mathrm{~W}$, respectively, with an elevation of $1475 \mathrm{~m}$. The table shows data levels from the surface through approximately $782 \mathrm{hPa}$.

\begin{tabular}{|c|c|c|c|c|c|}
\hline HGHT & PRES & TEMP & RELH & SPD & DIR \\
\hline m MSL & hPa & ${ }^{\circ} \mathbf{C}$ & \% & knot & deg \\
\hline 2134 & 782.3 & -16.5 & 50 & 6 & 65 \\
\hline 1829 & 814.7 & -15.1 & 50 & 5 & 60 \\
\hline 1688 & 830.0 & -14.5 & 51 & 3 & 75 \\
\hline 1634 & 836.0 & -14.3 & 55 & 3 & 81 \\
\hline 1553 & 845.0 & -14.1 & 75 & 2 & 90 \\
\hline 1508 & 850.0 & -16.1 & 78 & 1 & 95 \\
\hline 1483 & 853.0 & -17.3 & 78 & 0 & 24 \\
\hline 1475 & 854.0 & -18.7 & 78 & 0 & 0 \\
\hline
\end{tabular}

Note: Height (HGHT) is in m MSL, pressure (PRES) in hPa, temperature (TEMP) in ${ }^{\circ} \mathrm{C}$, relative humidity (RELH) in percent, wind speed (SPD) in knots and wind direction (DIR) in degrees.

The WRF grid point from which data were extracted to create the profiles of table 8 was nearly the same distance from the GJT site as the WRF grid point closest to the GJT site. Although only 
one grid point distant $(9 \mathrm{~km})$, the terrain database elevation for the grid point closest to GJT $(1408 \mathrm{~m})$ placed the model terrain below that observed at GJT. Thus no extrapolation was possible.

Table 8. Profiles generated from the WRF 9-km output for the same nominal time as for table 7 . The latitude, longitude, and elevation, to the nearest 0.01 degree and meter, respectively, are $39.16 \mathrm{~N}, 108.48 \mathrm{~W}$, and $1634 \mathrm{~m}$.

\begin{tabular}{|c|c|c|c|c|c|}
\hline HGHT & PRES & TEMP & RELH & SPD & DIR \\
\hline m MSL & hPa & ${ }^{\circ} \mathbf{C}$ & \% & knot & deg \\
\hline 2138.8 & 781.9 & -15.9 & 62 & 1.4 & 10 \\
\hline 2044.6 & 791.7 & -15.2 & 58 & 1.7 & 23 \\
\hline 1962.4 & 800.4 & -14.5 & 54 & 2.5 & 35 \\
\hline 1892.0 & 807.9 & -14.0 & 52 & 3.5 & 38 \\
\hline 1825.8 & 814.9 & -13.6 & 49 & 4.5 & 38 \\
\hline 1767.4 & 821.2 & -13.3 & 47 & 5.5 & 34 \\
\hline 1716.5 & 826.7 & -13.1 & 46 & 6.6 & 28 \\
\hline 1673.2 & 831.5 & -13.2 & 46 & 7.7 & 22 \\
\hline 1644.7 & 834.6 & -17.6 & 65 & 6.5 & 30 \\
\hline 1634.1 & 835.9 & -17.9 & 67 & 6.9 & 30 \\
\hline
\end{tabular}

Note: Height (HGHT) is in m MSL, pressure (PRES) in hPa, temperature (TEMP) in ${ }^{\circ} \mathrm{C}$, relative humidity (RELH) in percent, wind speed (SPD) in knots and wind direction (DIR) in degrees.

Table 9 shows the WRF profiles of table 8 after extrapolation to the GJT elevation resulting in an extrapolation depth of $159 \mathrm{~m}$. The units are the same as in table 8. Figure 7 shows a comparison of the lower part of the radiosonde to the profiles from the 9-km WRF using both the old extrapolation method and the proposed extrapolation method. The surface temperature at the new surface found using the new extrapolation method is $0.4 \mathrm{~K}$ warmer than the observed value from the radiosonde, and is much closer $\left(1.4{ }^{\circ} \mathrm{C}\right)$ to the observed value than that found from the standard extrapolation method $\left(-16.9^{\circ} \mathrm{C}\right)$ that uses the standard lapse rate. Note also, that except for a shallow layer just above the new surface the temperature throughout the extrapolation layer from the new extrapolation method much more closely matches the observed profile than does the temperature from the standard extrapolation method. For example, at the old surface, the new extrapolation method is $0.9 \mathrm{~K}$ warmer than the radiosonde while the standard extrapolation method is $3.6 \mathrm{~K}$ cooler than the radiosonde. It is important to note that the extrapolation method cannot correct errors in the WRF output; the goal of improving the extrapolation technique is to create an extrapolated profile that is more consistent meteorologically with the model output than the standard extrapolation method. The extrapolated wind direction shows little difference from the standard method of using the surface value. This result is not surprising given the wind directions of the input profile. The extrapolated wind speeds are slightly closer to the radiosonde values than those extrapolated using the standard method, but both extrapolation methods result in considerably higher wind speeds than the observations. On the other hand, the extrapolated surface pressure is close to that found in the radiosonde sounding. 
Table 9. Profiles extrapolated from the WRF 9-km output in table 8. The extrapolation depth was $159 \mathrm{~m}$. The variables and units are the same as in table 8 except height is shown in both AGL and MSL. The levels where the extrapolated profile differs from the original profile in table 8 are highlighted. Note also that the four levels immediately above the surface in table 8 are omitted in the extrapolated profile because they were part of the surface-based inversion that has been moved to the new surface.

\begin{tabular}{|c|c|c|c|c|c|c|}
\hline HGHT & HGHT & PRES & TEMP & RELH & SPD & DIR \\
\hline m AGL & m MSL & hPa & ${ }^{\circ} \mathbf{C}$ & \% & knot & deg \\
\hline 1335.5 & 2810.6 & 714.7 & -20.1 & 68 & 0.6 & 167 \\
\hline 1169.8 & 2644.9 & 730.8 & -19.0 & 69 & 0.6 & 71 \\
\hline 1022.9 & 2498.0 & 745.3 & -18.1 & 69 & 1.1 & 37 \\
\hline 890.0 & 2365.1 & 758.7 & -17.4 & 68 & 1.4 & 25 \\
\hline 770.4 & 2245.5 & 770.9 & -16.7 & 65 & 1.4 & 14 \\
\hline 663.8 & 2138.9 & 781.9 & -15.9 & 62 & 1.4 & 10 \\
\hline 569.5 & 2044.6 & 791.7 & -15.2 & 58 & 1.7 & 23 \\
\hline 487.4 & 1962.5 & 800.4 & -14.5 & 54 & 2.5 & 35 \\
\hline 417.0 & 1892.1 & 807.9 & -14.0 & 52 & 3.5 & 38 \\
\hline 350.8 & 1825.9 & 814.9 & -13.6 & 49 & 4.5 & 38 \\
\hline 159.0 & 1634.1 & 835.8 & -13.4 & 47 & 6.2 & 30 \\
\hline 82.5 & 1557.6 & 844.3 & -13.3 & 56 & 6.4 & 30 \\
\hline 0.0 & 1475.1 & 853.6 & -18.3 & 67 & 6.5 & 30 \\
\hline
\end{tabular}




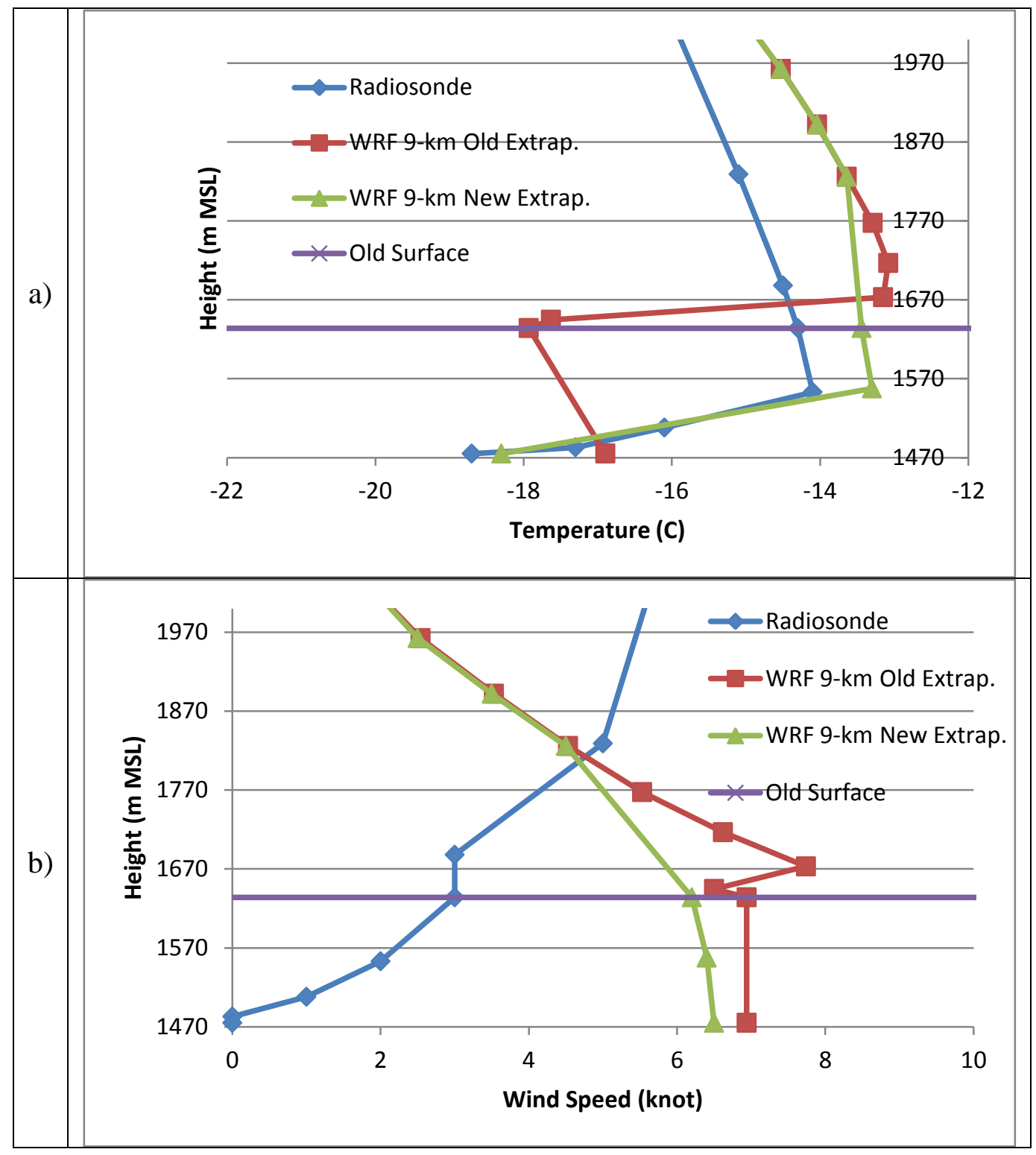

Figure 7. Profiles comparing the 12 UTC 14 January 2013 GJT radiosonde to 9-km WRF data extended from the "old surface" to the radiosonde surface using the standard extrapolation and the extrapolation method proposed here for (a) temperature and (b) wind speed.

Additional runs compared the same radiosonde sounding to WRF output for 3- and 1-km grids. However, in the 3-km output the nearest useful WRF location (i.e., a location with a model terrain height greater than the radiosonde) was two grid points away from the radiosonde site and, for the 1-km output, the nearest useful location was four grid points distant. Nevertheless, the terrain database elevations for the respective WRF locations were very close to that for the 9-km data. In part that may be a result of different terrain resolutions and smoothing for use with the different model grids. Tables 10 and 11 present the 3-km WRF profiles before and after 
application of the extrapolation procedure. The surface temperature is higher than for the 9-km WRF output and the near surface wind speeds are slightly lower. Figure 8 plots the lower portions of the profiles from the radiosonde as compared to the 3-km WRF profile extrapolated both using the standard method and the new method.

Table 10. Profiles generated from the WRF 3-km output for the same nominal time as for table 8. The latitude, longitude, and elevation are $39.16 \mathrm{~N}$, $108.48 \mathrm{~W}$, and $1648 \mathrm{~m}$, to the nearest 0.01 degree and meter, respectively. The variables and units are the same as in table 8 .

\begin{tabular}{|c|c|c|c|c|c|}
\hline HGHT & PRES & TEMP & RELH & SPD & DIR \\
\hline m MSL & hPa & ${ }^{\circ} \mathbf{C}$ & \% & knot & deg \\
\hline 2153.2 & 780.6 & -15.7 & 60 & 1.2 & 42 \\
\hline 2058.9 & 790.4 & -14.9 & 56 & 1.5 & 40 \\
\hline 1976.7 & 799.1 & -14.2 & 53 & 2.0 & 39 \\
\hline 1906.2 & 806.5 & -13.6 & 51 & 2.6 & 38 \\
\hline 1839.9 & 813.6 & -13.2 & 48 & 3.5 & 36 \\
\hline 1781.3 & 819.9 & -12.8 & 46 & 4.4 & 32 \\
\hline 1730.4 & 825.4 & -12.4 & 44 & 5.6 & 26 \\
\hline 1686.9 & 830.1 & -12.2 & 42 & 6.8 & 21 \\
\hline 1658.2 & 833.2 & -15.9 & 54 & 9.1 & 28 \\
\hline 1647.6 & 834.4 & -16.3 & 56 & 9.7 & 28 \\
\hline
\end{tabular}

Table 11. Profiles extrapolated from the WRF 3-km output in table 10. The extrapolation depth was $173 \mathrm{~m}$. The variables and units are the same as in table 9. The levels where the extrapolated profile differs from the original profile in table 10 are highlighted. Note also that the three levels immediately above the surface in table 10 are omitted in the extrapolated profile because they were part of the surface-based inversion that has been moved to the new surface.

\begin{tabular}{|c|c|c|c|c|c|c|}
\hline HGHT & HGHT & PRES & TEMP & RELH & SPD & DIR \\
\hline m AGL & m MSL & hPa & ${ }^{\circ}$ C & \% & knot & deg \\
\hline 678.6 & 2153.2 & 780.6 & -15.7 & 60 & 1.2 & 42 \\
\hline 584.3 & 2058.9 & 790.4 & -14.9 & 56 & 1.5 & 40 \\
\hline 502.1 & 1976.7 & 799.1 & -14.2 & 53 & 2.0 & 39 \\
\hline 431.6 & 1906.2 & 806.5 & -13.6 & 51 & 2.6 & 38 \\
\hline 365.3 & 1839.9 & 813.6 & -13.2 & 48 & 3.5 & 36 \\
\hline 306.7 & 1781.3 & 819.8 & -12.8 & 46 & 4.4 & 32 \\
\hline 173.0 & 1647.6 & 834.4 & -12.7 & 44 & 7.2 & 28 \\
\hline 39.3 & 1513.9 & 849.2 & -12.4 & 49 & 8.7 & 28 \\
\hline 0 & 1474.6 & 853.6 & -16.8 & 56 & 9.1 & 28 \\
\hline
\end{tabular}




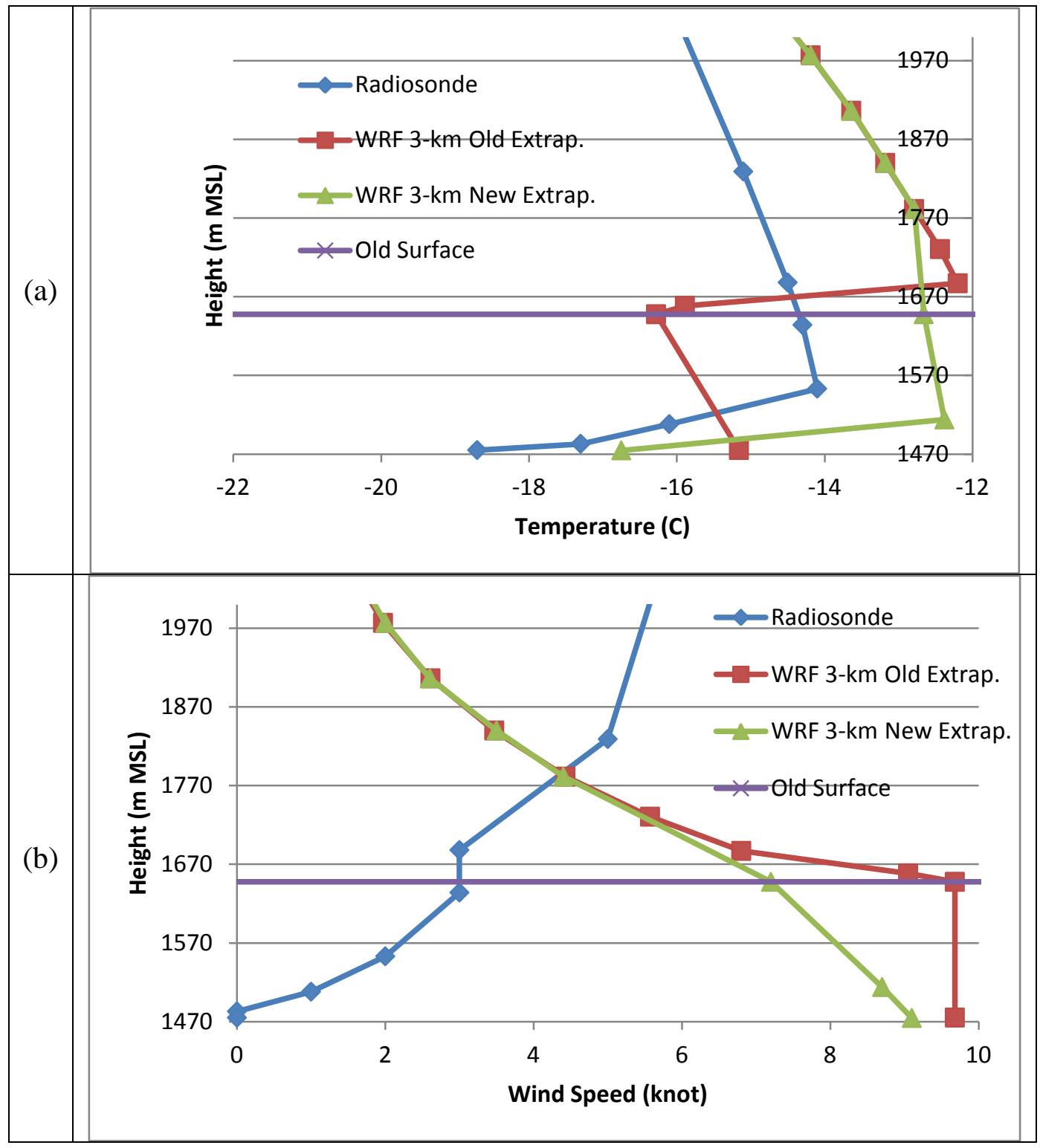

Figure 8. Profiles comparing the 12 UTC 14 January 2013 GJT radiosonde to 3-km WRF data extended from the "old surface" to the radiosonde surface using the standard extrapolation and the extrapolation method proposed here for (a) temperature and (b) wind speed.

The new extrapolation method somewhat decreased the surface temperature toward the radiosonde value as compared to the standard extrapolation method. The temperature at about $39 \mathrm{~m}$ AGL appears too high $\left(-12.4^{\circ} \mathrm{C}\right)$, but it is $0.2 \mathrm{~K}$ less than the initial WRF input value at the same height $\left(-12.2^{\circ} \mathrm{C}\right)$, and the inversion in the input data for the 0 to $39 \mathrm{~m}$ layer has nearly the same magnitude as in the output. However, the surface temperature relative to the radiosonde value is still an improvement over the standard method, where the surface temperature is $-15.2{ }^{\circ} \mathrm{C}$. More importantly given the original WRF profile, the temperature profile using the new extrapolation method is more consistent with what one would expect meteorologically than 
the profile created by the standard extrapolation method (figure 8a). It is encouraging to note that the shape of the profile from the new extrapolation method also more closely matches the rawinsonde than the standard extrapolation method. The wind directions are close to the input values as before. As before, the surface pressure is close to the radiosonde sounding value.

The situation for the 1-km WRF data with an extrapolation depth of $140 \mathrm{~m}$ (not shown) is similar, but the surface temperature was higher as were the wind speeds and directions. The wind speeds are slightly corrected (i.e., closer to the radiosonde values) compared to the standard method. The wind directions are fairly close overall to the radiosonde in both the WRF profile and the extrapolated one, but both have about the same values and about the same difference relative to the radiosonde. The surface temperature of the input WRF profile was $-13.9^{\circ} \mathrm{C}$ and for the extrapolated profile it was $-14.0{ }^{\circ} \mathrm{C}$. That compares to the standard method's value of $-13.0^{\circ} \mathrm{C}$.

In all these cases, the surface temperature found by using the extrapolation method proposed here was somewhat closer than the standard method to the radiosonde's surface value of $-18.7^{\circ} \mathrm{C}$ for a fairly shallow inversion. However, as noted in section 2 (Method) the maximum allowable magnitude for inversion lapse rates may be changed to fit the local atmospheric situation. If we changed that value from the nominal $-15 \mathrm{~K} / \mathrm{km}$ to a value of $-100 \mathrm{~K} / \mathrm{km}$ for the run with the profile from the 3-km WRF data, which was closer to the lapse rate for the lowest prognostic layer $(-128.6 \mathrm{~K} / \mathrm{km}$ over $28.7 \mathrm{~m}$ from the WRF data), then the surface temperature came to $-18.1{ }^{\circ} \mathrm{C}$, which is about $1.3 \mathrm{~K}$ closer to the radiosonde value. The radiosonde sounding lapse rates for the first two layers ( 8 and $25 \mathrm{~m}$ thick, respectively) were -175 and $-48 \mathrm{~K} / \mathrm{km}$. If we set the maximum magnitude to a value above the observed maximum (e.g., $-150 \mathrm{~K} / \mathrm{km})$, then the computed surface value $\left(-18.5^{\circ} \mathrm{C}\right)$ came close to the observed value $\left(-18.7^{\circ} \mathrm{C}\right)$. This last surface temperature is not far from the one extrapolated from the 9-km WRF data with the nominal maximum allowable inversion lapse rate of $-15 \mathrm{~K} / \mathrm{km}$.

\subsubsection{Extrapolation Depth Less Than Inversion Depth}

In the case examined here, the sounding had a surface-based inversion that extended to a height of $337 \mathrm{~m}$ based on the radiosonde data (623 m using the WRF 9-km profile). Table 12 presents a sample sounding from ZXS. The time was 12 UTC on 12 January 2013. The 9-km gridded WRF data used here (at $53.78 \mathrm{~N}, 122.87 \mathrm{~W}$ with an elevation of $818 \mathrm{~m}$ ) were for a location one grid point north and to the east of the nominally closest WRF grid point. Table 13 has the analogous WRF profiles of the meteorological variables. Table 14 lists the extrapolated WRF profile where the extrapolation depth was $217 \mathrm{~m}$, which is the difference between the grid point elevation of the ZXS site and that of the WRF terrain database for the selected grid point. We used a maximum inversion lapse rate magnitude of $-50 \mathrm{~K}$, which is in line with published data and less than the maximum magnitudes just above the surface in both the radiosonde and WRF data. A comparison of the lower portions of each of these profiles is shown in figure 9. 
Table 12. Input file from a radiosonde with a surface-based inversion of $337 \mathrm{~m}$ AGL for ZXS. Observations were at 12 UTC on 12 January 2013. Only the lines from the surface through $886 \mathrm{hPa}$ are shown. The variables and units are the same as in table 7 .

\begin{tabular}{|c|c|c|c|c|c|}
\hline HGHT & PRES & TEMP & RELH & SPD & DIR \\
\hline m MSL & hPa & ${ }^{\circ} \mathbf{C}$ & \% & knot & deg \\
\hline 1173 & 886.0 & -12.9 & 85 & 12 & 191 \\
\hline 971 & 910.0 & -15.9 & 97 & 11 & 194 \\
\hline 938 & 914.0 & -15.7 & 98 & 11 & 195 \\
\hline 914 & 916.9 & -16.3 & 98 & 11 & 195 \\
\hline 848 & 925.0 & -18.1 & 99 & 2 & 165 \\
\hline 692 & 945.0 & -22.9 & 86 & 1 & 57 \\
\hline 610 & 955.8 & -23.7 & 79 & 1 & 0 \\
\hline 609 & 956.0 & -23.7 & 78 & 1 & 0 \\
\hline 601 & 957.0 & -25.5 & 80 & 0 & 0 \\
\hline
\end{tabular}

Table 13. Profiles generated from WRF 9-km output for the same nominal time as for table 12. The latitude, longitude, and elevation, to the nearest 0.01 degree and meter, respectively, are $53.78 \mathrm{~N}, 122.87 \mathrm{~W}$, and $818 \mathrm{~m}$. The variables and units are the same as in table 8 .

\begin{tabular}{|c|c|c|c|c|c|}
\hline HGHT & PRES & TEMP & RELH & SPD & DIR \\
\hline m MSL & hPa & ${ }^{\circ} \mathbf{C}$ & \% & knot & deg \\
\hline 1150.6 & 887.7 & -11.0 & 49 & 2.4 & 259 \\
\hline 1078.9 & 896.0 & -11.3 & 50 & 2.1 & 247 \\
\hline 1011.7 & 903.9 & -11.6 & 50 & 2.1 & 239 \\
\hline 952.4 & 911.0 & -11.8 & 51 & 2.2 & 237 \\
\hline 901.0 & 917.1 & -12.1 & 51 & 3.2 & 227 \\
\hline 857.3 & 922.4 & -12.7 & 51 & 3.8 & 218 \\
\hline 828.5 & 925.9 & -17.4 & 68 & 3.7 & 196 \\
\hline 817.8 & 927.3 & -17.9 & 71 & 4.2 & 196 \\
\hline
\end{tabular}

Table 14. Extrapolated sounding or profile generated from the sounding of table 13. The extrapolation depth was $217 \mathrm{~m}$ (less than inversion height). The variables and units are the same as in table 8 . The levels where the extrapolated profile differs from the original profile in table 13 are highlighted.

\begin{tabular}{|c|c|c|c|c|c|c|}
\hline HGHT & HGHT & PRES & TEMP & RELH & SPD & DIR \\
\hline m AGL & m MSL & hPa & ${ }^{\circ} \mathbf{C}$ & \% & knot & deg \\
\hline 549.8 & 1150.6 & 887.7 & -11.0 & 49 & 2.4 & 259 \\
\hline 478.1 & 1078.9 & 896.0 & -11.3 & 50 & 2.1 & 246 \\
\hline 410.8 & 1011.6 & 903.9 & -11.6 & 50 & 2.1 & 239 \\
\hline 351.6 & 952.4 & 911.0 & -11.8 & 51 & 2.2 & 237 \\
\hline 300.2 & 901.0 & 917.1 & -12.1 & 51 & 3.2 & 227 \\
\hline 256.4 & 857.2 & 922.4 & -12.7 & 51 & 3.8 & 218 \\
\hline 227.6 & 828.4 & 925.9 & -17.4 & 68 & 3.7 & 196 \\
\hline 217.0 & 817.8 & 927.3 & -17.9 & 69 & 2.9 & 212 \\
\hline 0.0 & 600.8 & 954.9 & -23.3 & 71 & 3.7 & 196 \\
\hline
\end{tabular}




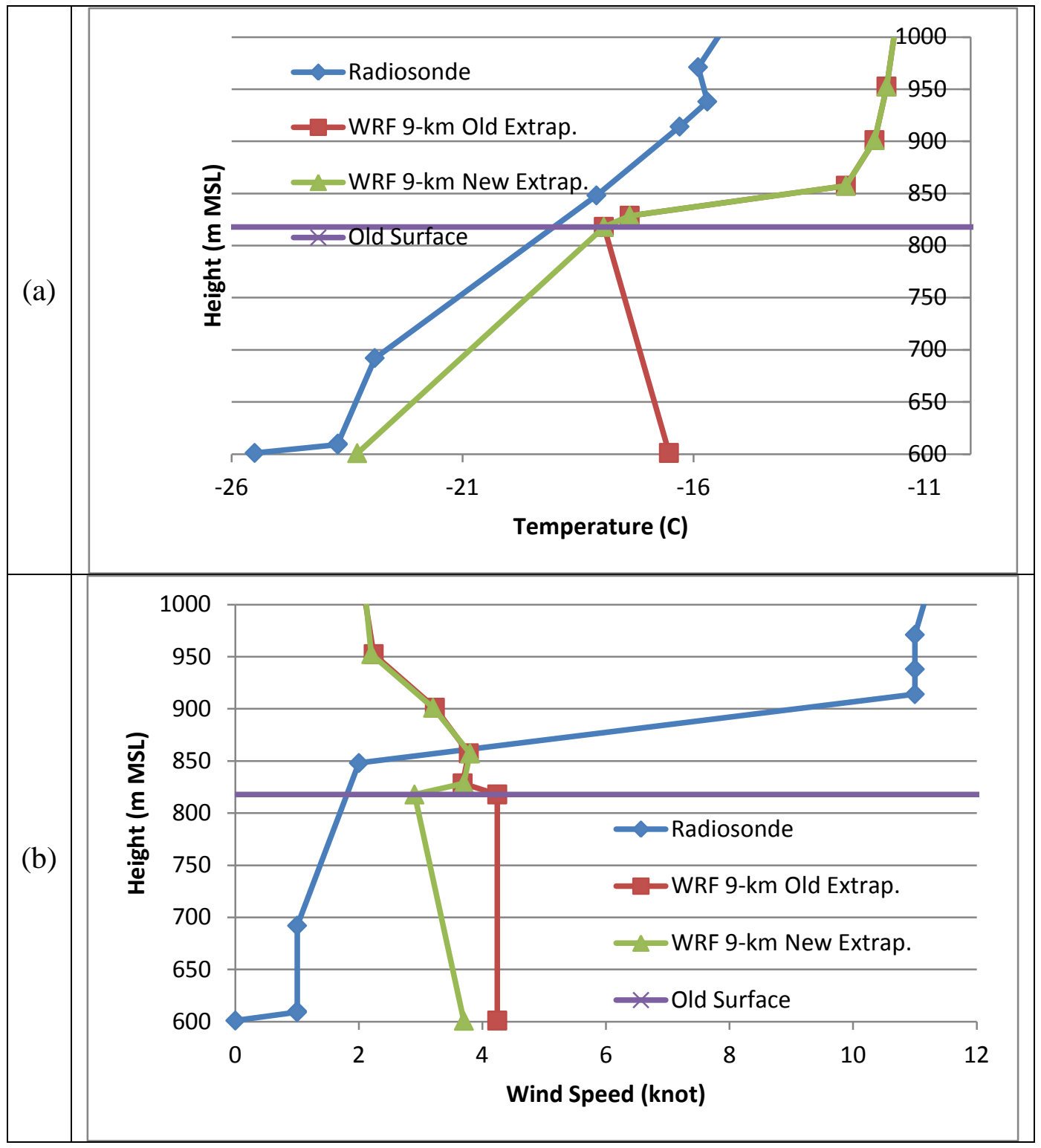

Figure 9. Profiles comparing the 12 UTC 12 January 2013 ZXS radiosonde to 9-km WRF data extended from the "old surface" to the radiosonde surface using the standard extrapolation and the extrapolation method proposed here for (a) temperature and (b) wind speed.

For this sample, the extrapolated surface temperature was about $2.2{ }^{\circ} \mathrm{C}$ higher than the observation, but that was a significant improvement over the standard method, which would have given a value of $-16.5^{\circ} \mathrm{C}\left(9^{\circ} \mathrm{C}\right.$ higher than the observation). As noted above, the WRF data for an hour earlier than the nominal time of the radiosonde may be closer in time to the radiosonde data for the lowest levels. For ZXS at 11 UTC, the extrapolated surface temperature $\left(-23.8^{\circ} \mathrm{C}\right)$ was a little more than $0.5 \mathrm{~K}$ closer to the radiosonde surface value of $-25.5^{\circ} \mathrm{C}$. 
As before, the wind speeds within the extrapolation layer were slightly closer to the radiosonde values than from the standard method, but both this method and the standard one were off from the measured values. Neither method did well with respect to wind direction, which was essentially 0 for the calm and nearly calm wind in the lowest layers of the ZXS sounding. The surface pressure was too low by $2.1 \mathrm{hPa}$ relative to the radiosonde data. Interestingly, the surface pressure at 00 UTC, 12 January 2013 and 12 UTC, 11 January 2013 was $954.0 \mathrm{hPa}$ both times. That suggests the model did not adjust rapidly enough for the rise in surface pressure.

Another WRF 9-km grid point was slightly closer to the ZXS site at $53.94 \mathrm{~N}$ and $122.87 \mathrm{~W}$, and had an elevation of $658.3 \mathrm{~m}$ (not shown here). The extrapolation depth was $57 \mathrm{~m}$ to the nearest meter. The extrapolated surface temperature came to $-23.9^{\circ} \mathrm{C}$, about $1.6^{\circ} \mathrm{C}$ warmer than the ZXS sounding. However, that difference was somewhat better than the standard method, which led to a surface value $2.0^{\circ} \mathrm{C}$ too high. The lowest level wind speeds using the WRF data at this location were about 1-2 knot larger than the nearly calm radiosonde values (except at the surface where the radiosonde showed a calm wind), and within several degrees in direction in the lowest levels above the surface. The standard method gave wind speeds and directions that were only very slightly further from the radiosonde values. On the other hand, the surface pressure was $2.7 \mathrm{hPa}$ too low, a $0.6 \mathrm{hPa}$ larger difference than for the other WRF location.

WRF-derived profiles (not shown) also were compared for two nearby 1-km grid points not far from the ZXS radiosonde site. The points were located at $53.88 \mathrm{~N}$ and $122.84 \mathrm{~W}$ and $53.86 \mathrm{~N}$ and $122.87 \mathrm{~W}$, respectively, slightly to the west and south of the radiosonde site. The respective elevations were $673 \mathrm{~m}$ and $762 \mathrm{~m}$ vs. $601 \mathrm{~m}$ at the radiosonde site. Both temperature profiles had inversion heights greater than the extrapolation depth $(416 \mathrm{~m}$ vs. $72 \mathrm{~m}$ and $334 \mathrm{~m}$ vs. $161 \mathrm{~m}$, respectively). The WRF surface temperatures were -19.2 and $-16.3^{\circ} \mathrm{C}$, respectively. The extrapolated temperatures deviated more from the radiosonde value than when using the $9-\mathrm{km}$ gridded data, but provided significantly better values than the standard method for this comparison on the 1-km domain. The surface temperatures from the method of this report versus those from the "standard" procedure were $-22.1{ }^{\circ} \mathrm{C}$ versus $-18.7{ }^{\circ} \mathrm{C}$ and $-19.6^{\circ} \mathrm{C}$ versus $-15.3^{\circ} \mathrm{C}$. The radiosonde surface temperature was $-25.5^{\circ} \mathrm{C}$. Though the WRF locations were close to the radiosonde site, the differences in terrain between the database and the actual values may have contributed to the difference between the extrapolated and measured surface temperatures.

Land use or type of terrain can affect the model and in turn affect the extrapolation. We examined a sounding from PANC $(61.16 \mathrm{~N}$ and $-150.01 \mathrm{~W}$, elevation of $40 \mathrm{~m})$ for $12 \mathrm{UTC}, 8$ January 2013 (not shown). For the 9-km gridded WRF data, the nearby locations had inversions that were much shallower than the differences in elevation between the model and the radiosonde and therefore much shallower than the extrapolation depth. For the 1-km gridded data, one nearby location had an inversion greater than the extrapolation depth, but the extrapolation only 
covered $17 \mathrm{~m}$. In this case, either the proposed or standard method should provide a useful result. In fact, the standard method yielded a result only $0.2{ }^{\circ} \mathrm{C}$ too warm, and the proposed method gave a temperature $0.4{ }^{\circ} \mathrm{C}$ too cold. However, when we dropped the subtraction of the difference between the temperature at the second level above the surface and the surface temperature, the extrapolated surface temperature was nearly the same as the radiosonde value, less than $0.1{ }^{\circ} \mathrm{C}$ too cold. This result suggests that locations near a coastline should be treated somewhat differently than those further inland since a major body of water nearby the radiosonde site could warm the near surface atmosphere reducing the intensity of an inversion. Further work is needed to check if a slightly different procedure can provide a better outcome for more than this one case.

\subsubsection{Other Considerations}

Here we look at other parameters such as the maximum height of surface wind influence $\left(\mathrm{h}_{\max }\right)$. For this section, $\mathrm{h}_{\max }$ was decreased from $400 \mathrm{~m}$ to $100 \mathrm{~m}$ and then increased to $800 \mathrm{~m}$ for the WRF profile of table 8 . Where there is an inversion, a smaller value of $h_{\max }$ is not unreasonable. Using the lower height $\left(\mathrm{h}_{\max }=100 \mathrm{~m}\right)$ resulted in a profile of wind speed slightly closer to the radiosonde profile for the lower part of the extrapolation layer, that is, a few tenths of a knot less than before, but still too high. The higher value of $h_{\max }(800 \mathrm{~m})$ as well as overall for the lower value $(100 \mathrm{~m})$ led to slightly higher wind speeds, that is, up to a few tenths of a knot higher than for $\mathrm{h}_{\max }$ of $400 \mathrm{~m}$ and thus farther from the observed values. The wind direction was very slightly less for the lower height (about 1 degree), but there was no significant change. These results were not surprising since the wind directions did not change significantly over the first nine levels of the WRF sounding (through about $400 \mathrm{~m}$ AGL). The wind speeds did change for heights above about 200 m AGL (first seven levels of the WRF sounding), but only by fairly small magnitudes over the levels used for the wind extrapolation.

However, to check the sensitivity of the results to vertical wind direction gradients above the two lowest profile levels (surface and one above), we increased the magnitude of the wind direction by 60 degrees for the seven levels above those two lowest levels. When $\mathrm{h}_{\max }$ is $100 \mathrm{~m}$, the magnitude of the extrapolated wind direction is overestimated by about 30 degrees at the top of the inversion, but is fairly close to the observed value for the top of the extrapolation layer. For $\mathrm{h}_{\max }$ of $800 \mathrm{~m}$, the extrapolated wind directions for those two levels were underestimated by about 60 and 50 degrees, respectively.

A further issue is the difference in elevation and land use between any terrain database and the actual terrain. Those differences can contribute to deviations of an extrapolated surface temperature from the actual, and also could affect the near surface winds. 


\section{Summary and Conclusion}

This report proposes a method for taking profiles derived using coarser model terrain databases and extrapolating down to the actual elevations of sites or elevations from finer terrain databases. It also may be applied to radiosonde soundings or vertical profile data from other sources when the sounding location elevation is above the elevation of the site of application. The primary advantage appears to be for temperature when the input sounding has a surface-based inversion. The benefit for wind speed and direction, though small, also appears when there is some change in those variables nearer the surface. When the temperature lapse rate is near standard, the current method most often will be as good as or on occasion better than the method of this report, as one would expect. Similarly, if the wind speed and direction show very little change within the lowest few data levels, then the standard method should produce values about as well as the method of this report. The pressure values were usually very close relative to the radiosonde, but some were off by 2 to $3 \mathrm{hPa}$. In the end, a good WRF representation of the atmosphere at levels above the surface layers is needed to consistently provide good extrapolated values, but if the WRF profiles are not close to the observed profiles, then the extrapolated surface and nearsurface values will also be off from the actual. However, the method of this report still may lead to better surface and near surface temperatures than the current one, especially in the presence of inversions. By more effectively using the model profile information regarding the case-specific conditions, the new extrapolation method should be able to extrapolate downward in a way more meteorologically consistent with the model results than the standard extrapolation method.

Some comparisons were made between coarser grid model output and finer grid model output for the same geographical location (i.e., grid points for the same site). However, these comparisons have some important considerations as noted above. Comparisons of extrapolated model output to radiosonde soundings at locations very close to a radiosonde site may be more instructive since the extrapolation of the model profile is compared to observed values, but very often the model terrain for the given location is at a lower elevation than the radiosonde site or, at best, very close to the same elevation. However, a site where very nearby terrain is significantly higher provides the opportunity to compare WRF output with a nearly coincident radiosonde sounding. Nevertheless, even for locations only a few kilometers distant, the type of surface can have an important effect on the near surface atmosphere, such as a location near a large body of water. In the future, we will attempt to provide a means to take into account the factors that can have a significant impact on this or any updated extrapolation method. 


\section{References}

Katurji, M.; Zhong, S. The Influence of Topography and Ambient Stability on the Characteristics of Cold-Air Pools: A Numerical Investigation. J. Applied Meteorology and Climatology 2012, 51, 1740-1749.

Lee, J. A.; Kolczynski, W. C.; McCandless, T. C.; Haupt, S. E. An Objective Methodology for Configuring and Down-Selecting an NWP Ensemble for Low-Level Wind Prediction. Mon. Wea. Rev. 2012, 140, 2270-2286.

National Operational Hydrologic Remote Sensing Center, 2004. Snow Data Assimilation System (SNODAS) Data Products at NSIDC. Boulder, Colorado USA: National Snow and Ice Data Center. http://dx.doi.org/10.7265/N5TB14TC

Office of the Federal Coordinator for Meteorological Services and Supporting Research (OFCM), Federal Meteorological Handbook No. 3: Rawinsonde and Pibal Observations, FCM-H3-1997, Washington, DC, 1997, 191 pp.

Reen, B. P.; Stauffer, D. R.; Davis, K. J. Land-Surface Heterogeneity Effects in the Planetary Boundary Layer. Boundary-Layer Meteorology 2014, 150, 1-31.

Skamarock, W. C.; Klemp, J. B.; Dudhia, J.; Gill, D. O.; Barker, D. M.; Duda, M. G.; Huang, X.-Y.; Wang, W.; Powers, J. G. A Description of the Advanced Research WRF Version 3, NCAR Tech. Note NCAR/TN-475+STR. National Center for Atmospheric Sciences, Boulder, Colorado, USA, 125 pp, 2008.

Wang, W.; Bruyère, C.; Duda, M.; Dudhia, J.; Gill, D.; Kavulich, M.; Keene, K.; Lin, H-C.; Michalakes, J.; Rizvi, S.; Zhang, X.; Beezley, J., D.; Coen, J.; Mandel, J.; Chuang, H-Y.; McKee, N.; Slovacek, T.; Wolff, J. ARW: Version 3 Modeling System User's Guide - July 2013, Mesoscale \& Microscale Meteorology Division, National Center for Atmospheric Research, Boulder, CO, 411 pp, 2013.

White, P. W. (Ed), IFS DOCUMENTATION, CY25R1 (Operational implementation 9 April 2002), Part VI: Technical and computational procedures, Ch. 2.4 Vertical interpolations and extrapolations (http://www.ecmwf.int/research/ifsdocs/CY25r1/Technical/Technical-305.html), 2002, European Centre for Medium-Range Weather Forecasts (ECMWF), 164 pp.

Whiteman, C. D.; Zhong, S.; Shaw, W.J.; Hubbe, J. M.; Bian, X. Cold Pools in the Columbia Basin. Weather and Forecasting 2001, 16, 432-447. 


\section{List of Symbols, Abbreviations, and Acronyms}

$\begin{array}{ll}\text { AGL } & \text { above ground level } \\ \text { ARW } & \text { Advanced Research WRF } \\ \text { BC } & \text { British Columbia } \\ \text { ECMWF } & \text { European Centre for Medium-range Weather Forecasts } \\ \text { GFS } & \text { Global Forecast System } \\ \text { GJT } & \text { Grand Junction, CO, radiosonde location } \\ \text { GPS } & \text { global positioning system } \\ \text { MSL } & \text { mean sea level } \\ \text { MYJ } & \text { Mellor-Yamada-Janjić } \\ \text { NOHRSC } & \text { National Operational Hydrologic Remote Sensing Center } \\ \text { PANC } & \text { Anchorage, AK, radiosonde location } \\ \text { RH } & \text { relative humidity } \\ \text { SNODAS } & \text { Snow Data Assimilation System } \\ \text { UTC } & \text { universal time coordinated } \\ \text { WMO } & \text { World Meteorological Organization } \\ \text { WRF } & \text { Weather Research and Forecasting } \\ \text { ZXS } & \text { Prince George, BC, radiosonde location } \\ & \end{array}$




\section{List of Variables}

delta-h $=$ total depth of the layers included in sum-u and sum-v.

$\mathrm{h}_{\mathrm{ext}}=$ extrapolation depth $=\mathrm{z}_{\mathrm{oldsfc}}-\mathrm{z}_{\text {newsfc }}$

$\mathrm{h}_{\text {extmin }}=$ minimum extrapolation depth (do not use extrapolation if $\mathrm{h}_{\mathrm{ext}}<\mathrm{h}_{\mathrm{extmin}}$ )

$\mathrm{h}_{\mathrm{inv}}=$ depth of inversion

$\mathrm{h}_{\text {invmax }}=$ maximum allowed depth of inversion

$\mathrm{h}_{\max }=$ maximum height above the surface where surface wind influences wind

$\mathrm{h}_{\min }=$ maximum height where wind is considered equivalent to surface wind

$\mathrm{L}_{\mathrm{inv}}=$ lapse rate within the inversion

$\mathrm{L}_{\mathrm{m}}=$ mean lapse rate

$\mathrm{L}_{\text {aboveinv }}=$ mean lapse rate above the inversion (computed as for $\mathrm{L}_{\mathrm{m}}$, but ending at the top of the inversion vs. at the surface)

$\mathrm{L}_{\text {invmin }}=$ minimum lapse rate needed to diagnose an inversion

$\mathrm{L}_{\min }=$ minimum allowed lapse rate for calculating mean lapse rates

$\mathrm{L}_{\max }=$ maximum allowed lapse rate for calculating mean lapse rates

ratio $=$ ranges from one when $h_{e x t}=h_{\min }$ to zero when $h_{\text {ext }}=h_{\max }$

sum- $\mathrm{u}=$ sum of $\mathrm{u}$-layer $\mathrm{i}_{\mathrm{i}}$ over case-dependent layers - the total depth of the layers included is delta-h

sum-v = sum of v-layer ${ }_{\mathrm{i}}$ over case-dependent layers - the total depth of the layers included is delta-h

$\mathrm{u}$-layer $\mathrm{i}_{\mathrm{i}}=$ depth-coupled $\mathrm{u}$-component wind for layer $\mathrm{i}$

$\mathrm{u}_{\mathrm{m}}=$ mean depth weighted $\mathrm{u}$-component wind over case-dependent set of layers

v-layer $_{\mathrm{i}}=$ depth-coupled $\mathrm{v}$-component wind for layer $\mathrm{i}$

$\mathrm{v}_{\mathrm{m}}=$ mean depth weighted $\mathrm{u}$-component wind over case-dependent set of layers

$\mathrm{Z}_{\text {newsfc }}=$ new surface - the surface to which extrapolation is being completed 
$\mathrm{Z}_{\text {oldsfc }}=$ old surface - the surface in the input data

$\mathrm{Z}_{\mathrm{oldsfc}+1: 2}=$ first level above surface in radiosonde or second level above surface (i.e., second prognostic level) in WRF 


$\begin{array}{cl}1 & \text { DEFENSE TECH INFO CTR } \\ \text { (PDF) } & \text { ATTN DTIC OCA } \\ 2 & \text { US ARMY RSRCH LABORATORY } \\ (\text { PDF) } & \text { ATTN IMAL HRA MAIL \& RECORDS MGMT } \\ & \text { ATTN RDRL CIO LL TECHL LIB } \\ 2 & \text { US ARMY RSRCH LAB } \\ (\mathrm{PDF}) & \text { ATTN RDRL CIE } \\ & \text { J COGAN } \\ & \text { B REEN } \\ 1 & \text { GOVT PRNTG OFC } \\ \text { (PDF) } & \text { A MALHOTRA }\end{array}$


INTENTIONALLY LEFT BLANK. 